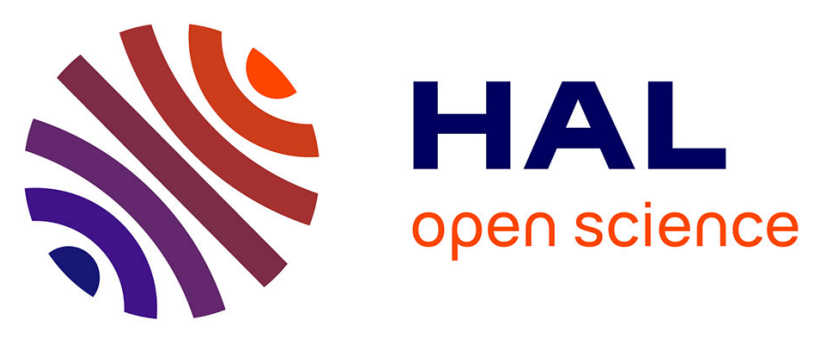

\title{
The dynamics and pH-dependence of Ag43 adhesins' self-association probed by atomic force spectroscopy
}

Adrien Jacquot, Chizuko Sakamoto, Angelina Razafitianamarahavo, Céline

Caillet, Jenny Merlin, Ahmad Fahs, Jean-Marc Ghigo, Jérôme F. L. Duval, Christophe Beloin, Grégory Francius

\section{To cite this version:}

Adrien Jacquot, Chizuko Sakamoto, Angelina Razafitianamarahavo, Céline Caillet, Jenny Merlin, et al.. The dynamics and pH-dependence of Ag43 adhesins' self-association probed by atomic force spectroscopy. Nanoscale, 2014, 6 (21), pp.12665 - 12681. 10.1039/c4nr03312d . pasteur-01381823

\section{HAL Id: pasteur-01381823}

https://hal-pasteur.archives-ouvertes.fr/pasteur-01381823

Submitted on 17 Nov 2016

HAL is a multi-disciplinary open access archive for the deposit and dissemination of scientific research documents, whether they are published or not. The documents may come from teaching and research institutions in France or abroad, or from public or private research centers.
L'archive ouverte pluridisciplinaire HAL, est destinée au dépôt et à la diffusion de documents scientifiques de niveau recherche, publiés ou non, émanant des établissements d'enseignement et de recherche français ou étrangers, des laboratoires publics ou privés.

\section{(1)(1) $\$(0)$}

Distributed under a Creative Commons Attribution - NonCommercial - ShareAlikel 4.0 


\section{Dynamics and pH-dependence of Ag43 adhesins self-association probed by Atomic Force Spectroscopy}

A. Jacquot, ${ }^{1,2}$ C. Sakamoto, ${ }^{3,4}$ A. Razafitianamaharavo, ${ }^{5,6}$ C. Caillet, ${ }^{5,6}$ J. Merlin, ${ }^{5,6}$ A. Fahs, ${ }^{1,2}$ J.M. Ghigo, ${ }^{3}$ J.F.L. Duval ${ }^{5,6}$, C. Beloin ${ }^{3}$ and G. Francius ${ }^{1,2^{*}}$

1 Université de Lorraine, Laboratoire de Chimie Physique et Microbiologie pour l'Environnement, UMR 7564, Villers-lès-Nancy, F-54601, France.

${ }^{2}$ CNRS, Laboratoire de Chimie Physique et Microbiologie pour l'Environnement, UMR 7564, Villers-lès-Nancy, F-54601, France.

${ }^{3}$ Institut Pasteur, Unité de Génétique des Biofilms, 25-28 rue du Dr Roux, Paris cedex 15, F75724, France.

${ }^{4}$ Université Paris Diderot, Sorbonne Paris Cité, Cellule Pasteur, rue du Dr Roux, Paris, F75015, France.

${ }^{5}$ Université de Lorraine, Laboratoire Interdisciplinaire des Environnements Continentaux, UMR 7360, Vandœuvre-lès-Nancy, F-54501, France.

${ }^{6}$ CNRS, Laboratoire Interdisciplinaire des Environnements Continentaux, UMR 7360, Vandœuvre-lès-Nancy, F-54501, France.

* Corresponding author:

Email: gregory.francius@univ-lorraine.fr

Phone: (33) 0383685236 


\begin{abstract}
Self-associating auto-transporter (SAAT) adhesins are two-domains cell surface proteins involved in bacteria auto-aggregation and biofilm formation. Antigen 43 (Ag43) is a SAAT adhesin commonly found in Escherichia coli whose variant Ag43a has been shown to promote persistence of uropathogenic E. coli within the bladder. The recent resolution of the tri-dimensional structure of the 499 amino-acids $\alpha$-domain in Ag43a has shed light on the possible mechanism governing the self-recognition of SAATs adhesins, in particular the importance of trans-interactions between the L shape $\beta$-helical scaffold of two $\alpha$-domains of neighboring adhesins. In this study, we use Single-Molecule Force Spectroscopy (SMFS) and Dynamic Force Spectroscopy (DFS) to unravel the dynamics of Ag43-self association under various $\mathrm{pH}$ and molecular elongation rates conditions that mimic the situations encountered by $E$. coli in its natural environment. Results evidenced an important stretchability of $\operatorname{Ag} 43 \alpha$ with unfolding of sub-domains leading to molecular extension as long as $150 \mathrm{~nm}$. Nanomechanical analysis of molecular stretching data suggested that self-association of Ag43 can lead to the formation of dimers and tetramers driven by rapid and weak cis- as well as slow but strong trans-interaction forces with magnitude as large as $100-250 \mathrm{pN}$. The dynamics of cis- and trans- interactions were demonstrated to be strongly influenced by $\mathrm{pH}$ and applied shear force, thus suggesting that environmental conditions can modulate Ag43mediated aggregation of bacteria at the molecular level.
\end{abstract}

\title{
Keywords:
}

Bacterial adhesins, Antigen 43, unwinding, molecular sliding, AFM 


\section{Introduction}

Bacterial adhesion onto abiotic surfaces and host tissues, as well as bacteria-bacteria interactions are key processes for colonization, biofilm formation and further infection. These different interactions are commonly mediated by surface appendages exposed at the bacterial cell surface. ${ }^{1,2}$ Large heteropolymeric appendages such as fimbriae are generally used by the bacteria to interact with surfaces over large separation distances, while shorter adhesins such as self-associating autotransporters (SAATs) adhesins transported by type $\mathrm{V}$ secretion are capable of promoting intimate interactions between bacteria. ${ }^{3,4}$ Prototypical members of this family of SAAT adhesins are AidA, an adhesin originally characterized in an E. coli O126:H27 strain isolated from a pediatric patient with diarrhea, ${ }^{5}$ TibA, first found in the ETEC O78:H11 strain H10407, ${ }^{6}$ and the Antigen 43 adhesin (Ag43), one of the most abundant outer membrane proteins in $E$. coli. ${ }^{7,} 8$ Like other AidA-I-type adhesin autotransporters, E. coli Antigen 43 is a short and rigid, monomeric adhesin composed of a Cterminal integral outer membrane $\beta$ domain through which is exported a $\mathrm{N}$-terminal passenger $\alpha$ domain $(\operatorname{Ag} 43 \alpha){ }^{9},{ }^{10}$ After its autocatalytic cleavage, Ag43 $\alpha$ (499 aa) remains loosely anchored to $\operatorname{Ag} 43 \beta$ domain and forms a $\beta$-strand helix that protrudes $10 \mathrm{~nm}$ from the cell surface. ${ }^{11-14}$ Like other AidA-I-type adhesin autotransporters, this adhesin is able to promote cell-cell interactions, and subsequent bacterial autoaggregation ${ }^{11,15}$ and biofilm formation ${ }^{3,}$ 16-18 through homomeric recognition of its $\alpha$-domain potentially folded as a $\beta$ helix. Some Ag43 variants have been further shown to facilitate the persistence of uropathogenic E. coli within the bladder, ${ }^{19,}{ }^{20}$ to promote uptake of- and resistance to- antimicrobial agents and

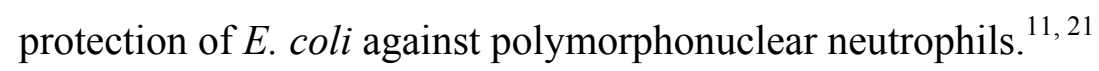

In 2011, the structure of the $\alpha$-domain of the AT Hap protein from Haemophilus influenzae was resolved, which opened a route for elucidating the relationship between structure and homophilic interaction mechanisms of the SAATs. ${ }^{22}$ In the Hap protein, homophilic 
recognition is promoted by the interaction in trans configuration of the $\alpha$-domain along a 7 turn right-handed $\beta$-helix, with $\sim 19$ residues in each turn. More recently, Heras et al. resolved the crystallographic structure of the Ag43a variant $\alpha$-domain of uropathogenic E. coli strain CFT073. ${ }^{14}$ As previously predicted, ${ }^{11}$ they demonstrated that the functional 499 amino-acids $\alpha$-domain of this SAAT protein is a 3 stranded $\beta$-helix structure comprising 23 complete turns with an average of 20 amino-acids per turn, each turn being composed of three faces marked by the arrows depicted in Figure S2, thus forming a triangular structure. Interestingly, Ag43a $\alpha$ displays a twisted L-shaped $\beta$-helical structure that plays a major role in the selfassociation and cell aggregation via a molecular "Velcro-type" mechanism where the dimerization of the $\alpha$-domain is ensured by multiple hydrogen bonds between the two twisted beta-helical structure coil around each other in a trans/head-to-tail configuration. ${ }^{14} \mathrm{~A}$ modeling of the $\alpha$-domain of $E$. coli $\mathrm{K}-12 \mathrm{Ag} 43$ that share $81.7 \%$ identity with that of UPEC CFT073 Ag43a, revealed that this domain also probably displays a twisted L-shaped $\beta$-helical structure (Figure S2). However, little is known on the self-association of beta-helical proteins, in particular its dynamics, its dependence on medium composition including $\mathrm{pH}$, and the way it is connected to the intrinsic mechanical and structural properties of the interacting proteins domains. These key issues remain difficult to address at the nanoscale from crystallography or X-ray scattering techniques (SAXS, WAXS) and macroscopic observations of self-aggregation of bacterial cells are useless in this perspective too.

Since the last decade, derivative techniques of atomic force microscopy (AFM) were developed for probing the physico-chemical properties of biomolecules. ${ }^{23-26}$ Techniques such as Dynamic Force Spectroscopy (DFS) and Single-Molecule Force Spectroscopy (SMFS) now allow access to molecular dynamic processes, chemical or surface reactivity, conformational properties, and interactions between single molecules. ${ }^{27,}{ }^{28}$ For the sake of example, Single-Molecule Force Spectroscopy (SMFS) was recently used to unravel and 
explain the binding mechanism of BCAM0224 auto-transporter adhesins involved in respiratory infections and secreted by Burkholderia cenocepacia. ${ }^{29}$ The authors evidenced that the BCAM0224 adhesin behaves like a nanospring when subjected to external shear forces and can form both homomeric and heteromeric interactions that enhance adhesion to immune cells with corresponding forces as large as $120 \mathrm{pN} .{ }^{29}$ Using a similar technique, the nanomechanical properties of LapA adhesin expressed by Pseudomonas fluorescens, or type 1 fimbriae attached to mannose were investigated under various $\mathrm{pH}$, ionic strength and shear force conditions. $^{30,31}$

In this work, we report a systematic investigation of the impact of solution $\mathrm{pH}$ and externally applied shear force on the dynamics of E. coli K-12 Ag43 $\alpha$-domain $(\operatorname{Ag} 43 \alpha)$ unfolding and molecular self-association. The conditions tested in this work mimic those met by E. coli cells in their natural environment. Our experiments are carried out using functionalized AFM probes specific to $\mathrm{Ag} 43 \alpha$ interacting with either model surfaces functionalized by $\mathrm{Ag} 43$ adhesins or with Ag43-decorated E. coli K-12 cells. Retraction force curves were recorded at different $\mathrm{pH}$ values ranging from 3 to 9 and were analyzed on the basis of the Worm Like Chain (WLC) model in order to quantify the impact of $\mathrm{pH}$ on the conformation properties of Ag43 structure. Dynamic force spectroscopy (DFS) measurements were further performed to investigate the dynamics of Ag43 self-association and unfolding under a wide range of $\mathrm{pH}$ and pulling rate conditions. Results obtained from DFS and SMFS experiments were finally supported by macroscopic bacterial auto-aggregation assays. We show that self-association forces between Ag43 $\alpha$-domains are mainly driven by trans interactions of $\alpha$-domains as strong as $100-250 \mathrm{pN}$, and we suggest the further contributions of possible cis interactions between these domains at sufficiently large values of $\mathrm{pH}$ and elongation rate. In addition, the existence of a tetrameric structure composed of Ag43 dimers is hypothesized from inspection of molecular stretching data collected by AFM. Such structure results from the coexistence of 
trans- and cis- interactions, and its existence is mediated by the lifetime of these interactions and by the solution $\mathrm{pH}$ conditions. Our results bring novel information on the mechanical properties of $\beta$-helical proteins and on the dynamics of their homomeric interactions.

\section{Results}

\section{AFM nanogold-mediated analysis of cells expressing or not Ag43 adhesins.}

The surface properties (morphology and adhesion) of E. coli K-12 cells constitutively producing or not Ag43 (E2498 and E2152, respectively) were investigated by AFM in PeakForce Mapping TM mode using a functionalized His-Ag43 $\alpha$ coated tip where the histidine tag was fused at the $\mathrm{N}$-terminal part of $\operatorname{Ag} 43 \alpha$-domain. The obtained adhesion maps collected with the functionalized AFM-tip (Figure S1) revealed that the only E2498 strain exhibited a moderately adhesive bacterial cell wall surface. These results confirmed the presence of Ag43 adhesins over the cell wall of the E2498 strain and they further highlight the specific self-recognition of Ag43 located at the bacterial surface and on the AFM tip. To further localize the Ag43 adhesins by virtue of $\operatorname{Ag} 43 \alpha-\operatorname{Ag} 43 \alpha$ homomeric interactions, we imaged bacterial cells constitutively producing Ag43 or not after incubation with nanogold particles grafted with His-Ag43 $\alpha$ where the histidine tag is fused at the N-terminal part of Ag43 $\alpha$-domain. When experiments were performed with cells E2498 constitutively expressing Ag43, we observed the presence of spherical structures 20 to $200 \mathrm{~nm}$ in diameter over and around the bacterial cells (Figure 1a, white arrows). NTA-nanogold particles are 5 $\mathrm{nm}$ in diameter before functionalization and the estimated size of $\operatorname{Ag} 43 \alpha$ domain is $10 \mathrm{~nm}$. Large structures $(>20 \mathrm{~nm})$ are then supposedly composed of 10-25 nm diameter substructures interacting following homomeric recognition of $\operatorname{Ag} 43 \alpha$. These large structures did not 
correspond to aggregated nanogold particles and their observation depended on the presence of Ag43 on the E. coli cell surface since they were not detected for the strain E2152 deleted for the agn43 gene (Figure 1b). These results support that the presence of the aforementioned structures results from homomeric interactions taking place between $\operatorname{Ag} 43 \alpha$ carried by nanogold and $\operatorname{Ag} 43 \alpha$ located at the E. coli cell surface. The presence of structures with characteristic dimensions of $c a 200 \mathrm{~nm}$ suggested that more than two molecules of $\mathrm{Ag} 43 \alpha$ may interact in order to form such large complexes.

\section{Analysis of Ag43 $\alpha$ self-association by dynamic force spectroscopy}

The dynamics of the adhesin conformational structure during self-recognition process is an important issue to address for understanding the auto-aggregation mechanism and the nature of the underlying protein-protein interactions. Single Molecule Force Spectroscopy (SMFS) and Dynamic Force Spectroscopy (DFS) are very relevant tools in that respect because they enable the analysis of the protein conformational changes and dynamics thereof during protein-protein interactions on living cell surfaces. ${ }^{28,36}$ Therefore, combined SMFS and DFS experiments were performed here in order to (i) evaluate the interaction forces taking place between two Ag43 $\alpha$-domains, (ii) investigate the dynamics of unfolding, and (iii) address the impact of $\mathrm{pH}$ and external shear forces on the protein conformational and structural features. First, both gold surfaces and gold AFM-tips were functionalized by the histidine-tagged Ag43 $\alpha$ after thiol-NTA grafting (N-ter fusion). The typical force curves corresponding to the interaction between Ag43 $\alpha$-functionalised gold surface and $\mathrm{Ag} 43 \alpha$-functionalised gold AFMtip are reported in Figure 2 at pH 7.4 for 100 and $3200 \mathrm{~nm} / \mathrm{s}$ pulling rate conditions and in Table 2 for intermediate values of pulling rates. The corresponding statistic distribution of the number of rupture events observed while retracting the modified-tip from the Ag43-modified surface are further displayed in Figure 2. The specificity of the functionalized AFM tips to 
Ag43 $\alpha$ was certified from the absence of interaction between nude gold surfaces and the modified tips (data not shown). Figure 2 displays qualitatively similar retraction force curves for 100 and $3200 \mathrm{~nm} / \mathrm{s}$ pulling rates with the presence of multiple adhesive events. While such event could be detected for tip to surface separation distance as large as $150 \mathrm{~nm}$ at $3200 \mathrm{~nm} / \mathrm{s}$ pulling rate (Figure 2b and Figure S4), Ag43 $\alpha$ uncoiling was observed over significantly shorter separation distances $(40-70 \mathrm{~nm})$ at $100 \mathrm{~nm} / \mathrm{s}$ (Figure 2a and Figure S4). Overall, the unfolding distance appears 5 to 15 times larger than the putative size of the folded adhesin of $10 \mathrm{~nm}$ dimension, which reflects a significant stretchability of this protein. The structured part of the $\alpha$-domain is supposedly folding as 23 complete coils with each spiral pitch containing an average of 20 amino acids $\left({ }^{14}\right.$ and Figure S2). Since the minimal force required to totally and concomitantly unfold two $\beta$ helical structures is above $400 \mathrm{pN},{ }^{37}$, ${ }^{38}$ this means, theoretically, that only one $\beta$ helical structure can be totally unfolded and thus a maximum of 23 rupture events should be observed by force spectroscopy measurements (note that the typical range of measured rupture force for self-associated $\mathrm{Ag} 43 \alpha$ is $c a .100-200 \mathrm{pN}$, cf. Table 2). The average number of ruptures per force curve we found decreased from $7 \pm 3$ to $3 \pm 2$ when the pulling rate was increased from 100 to $3200 \mathrm{~nm} / \mathrm{s}$ (Figures $2 \mathrm{c}$ and $\mathbf{2 d}$ ). These results evidenced a sequential unfolding of the interacting $\alpha$-domains but with a maximum of only 5 to 10 ruptures. Basically, this suggests that the interaction between two $\alpha$-domains breaks up before complete unfolding of the structures is achieved. Additionally, this result indicates that $\mathrm{Ag} 43 \alpha$ is folded in several domains composed of multiple turns, and consequently the unfolding is sequential and takes place domain after domain and not turn after turn.

The retraction force curves depicted in Figure 2 were further analyzed according to the Worm like Chain (WLC) model (eq 1) according to the methodology we detailed elsewhere. ${ }^{39}$ 
Briefly, this theoretical approach allowed the evaluation of several key parameters pertaining to the structural properties of $\mathrm{Ag} 43 \alpha$ and to their homomeric interactions:

- the persistence length $l_{\mathrm{p}}$ reflecting the intrinsic flexibility of the protein;

- the contour length $L_{\mathrm{c}}$ defined as the length of the fully extended protein;

- the rupture force between two proteins;

- the number of monomers, denoted as $N$, for the stretched system.

The statistic distribution of the last rupture force magnitude detected in the Force volume Image (FVI) and the number of monomers extracted from the retraction force curves are collected in Figure 3 for pulling rates of 100 and $3200 \mathrm{~nm} / \mathrm{s}$ at $\mathrm{pH} 7.4$. The rupture forces measured between two adhesins were not significantly modified by the pulling rate, with values of $138 \pm 35 \mathrm{pN}$ and $141 \pm 60 \mathrm{pN}$ at the two rate values adopted here. These values of rupture force measured onto model $\mathrm{Ag} 43 \alpha$-gold coated surfaces are comparable with those measured on living cells (Figure S1a-3). Moreover, the statistical analysis of $N$, corresponding to the number of monomers within the Ag43-Ag43 system, is bimodal, which suggests that at least 2 sub-structures were stretched during the retraction of the AFM-tip from the functionalized gold surface. We hereafter refer to $N_{1}$ and $N_{2}$ (with $N_{1}<N_{2}$ ) these two values taken by $N$, as illustrated in Figure 3c,d. We obtained $N_{1}=422 \pm 224$ and $N_{2}=1465 \pm$ 272 at $100 \mathrm{~nm} / \mathrm{s}$, and $N_{1}=418 \pm 156$ and $N_{2}=1938 \pm 711$ at $3200 \mathrm{~nm} / \mathrm{s}$ (see Table 2). .In order to address the nature of the two types of substructures probed by force spectroscopy at 100 and $3200 \mathrm{~nm} / \mathrm{s}$ and $\mathrm{pH} \mathrm{7.4,} \mathrm{we} \mathrm{plotted} \mathrm{in} \mathrm{Figure} \mathbf{S 5}$ the persistent length derived from WLC analysis as a function of the corresponding number of monomers $N$. The data clearly evidence the presence of two distinct clouds of points corresponding to the two searched substructures. In details, one may discriminate a substructure $(1000 \leq N \leq 2500)$ with a persistence length $l_{\mathrm{p}}$ lower or equal to $0.15 \mathrm{~nm}$, and a second type of substructure $(100 \leq N$ $\leq 1000$ ) with a $l_{\mathrm{p}}$ satisfying $l_{\mathrm{p}}>0.15 \mathrm{~nm}$. The former corresponds to a weak stretching of C-C 
bonds and the latter to the stretching of amino acids. Indeed, the length of a $\mathrm{C}-\mathrm{C}$ bond is in the range $0.12-0.15 \mathrm{~nm}$, which comes to state that all persistence lengths larger than this value must necessarily correspond to amino acids. Figure 3 shows that the bimodal distribution in terms of number of monomers does not depend on the pulling rate value. Additional experiments further show that the aforementioned bimodal distribution is not significantly affected with changing the solution $\mathrm{pH}$ (Figure S6 and Table 3).

Interestingly, a statistical switch in the respective weight distribution of the two substructures probed by force spectroscopy is observed with increasing the pulling rate from 100 to 3200 $\mathrm{nm} / \mathrm{s}$, as judged from the comparison between data collected in Figure $3 \mathrm{c}$ and Figure $3 \mathrm{~d}$. In details, the probability to observe the stretching of amino acids $\left(N_{1} \sim 500\right)$ was about $35 \%$ at $100 \mathrm{~nm} / \mathrm{s}$ and increased to $57 \%$ with increasing pulling rate to $3200 \mathrm{~nm} / \mathrm{s}$. For an intermediate value of the pulling rate $(400 \mathrm{~nm} / \mathrm{s})$, an iso-distribution of the two substructures is even reached regardless of the $\mathrm{pH}$ conditions (Figure S6). These results highlight the intrinsic dependence of the extent of stretching of the $\mathrm{C}-\mathrm{C}$ bonds and that of the amino acids on the applied pulling rate. To put it a nutshell, a slow elongation dynamics (low pulling rate values) predominantly favors the stretching of large assemblies of amino acids (Figure S5) whereas faster elongation dynamics (probed at higher pulling rates) goes in pair with a stretching of smaller $\mathrm{C}-\mathrm{C}$ bonds. The number of monomers corresponding to the amino acid structures is in the range 100 to 1000 (Figure S5). However, the complete stretching of two $\beta$ helical structures of Ag43 should lead to a number of monomers equal to $499 \times 2$ amino acids [REFERENCE]. Obviously then, the rupture forces in our experiments $(\leq 216 \mathrm{pN}$, see Table 3) are not large enough to totally unfold simultaneously two $\beta$ helical structures, which is in agreement with the literature $(250 \mathrm{pN}$ at least are required to unfold two $\beta$ helical structures) (REFS). 


\section{Effect of $\mathrm{pH}$ and pulling rate conditions on the dynamics of Ag43 unfolding}

In order to further investigate the changes in Ag43 conformation and structure during selfassociation of the proteins, force spectroscopy experiments were carried out at different pulling rates in the range $100-3200 \mathrm{~nm} / \mathrm{s}$ with varying the solution $\mathrm{pH}(5.2,6.1,7.4,8.1$ and 9.2). We emphasized that the pulling rate set in the force spectroscopy experiments basically fixes the time window where the self-association modes of the $\operatorname{Ag} 43 \alpha$ domains can be observed. Stated differently, with increasing the pulling rate, one will probe the fastest $\operatorname{Ag} 43 \alpha$ association mode and, conversely, the lower the pulling rate, the more efficient will be the observation of the slower association mechanisms. In fine, varying the pulling rate allows us to modulate the measurement timescale and thus to vary the so-called Deborah number defined here as the ratio between $\operatorname{Ag} 43 \alpha$ association timescale and measurement timescale.

Force curves similar to those given in Figure 2 were then recorded as a function of $\mathrm{pH}$ and analyzed on the basis of the WLC model. A marked dependence on $\mathrm{pH}$ and pulling rate was detected for the maximal molecular extension denoted as $L_{\max }$ (corresponding to the maximal rupture distance of self-associated Ag43, Figures $4 \mathbf{a}$ and $\mathbf{4 b}$ ) and the magnitude of the last rupture force was further found to be strongly modulated by $\mathrm{pH}$ too (Figure $\mathbf{4 c}$ and $\mathbf{4 d}$ ). In details, $L_{\max }$ varied with $\mathrm{pH}$ according to a sigmoid-like dependence and reached plateau values at sufficiently low and large $\mathrm{pH}$ values. For the lowest pulling rate tested in this work $(100 \mathrm{~nm} / \mathrm{s}$, Figure 4a), the plateau value under acid conditions was about $40 \mathrm{~nm}$ (corresponding $\mathrm{pH}$ range: 5 to 7), while the plateau reached at $\mathrm{pH}$ values larger than 9 was 80 $\mathrm{nm}$. For higher pulling rates $(3200 \mathrm{~nm} / \mathrm{s}$, Figure 4b), the same trend was observed, albeit with slightly higher plateau values reached by $L_{\max }$ for $\mathrm{pH}<7(50-65 \mathrm{~nm})$ and $\mathrm{pH}>9(100-150$ $\mathrm{nm})$. In addition, the magnitude of the last detected rupture force depended on $\mathrm{pH}$ according to a bell-shaped curve regardless of the pulling rate value adopted in the experiments. At low pulling rates, a shallow maximum is obtained around neutral $\mathrm{pH}$ with a value of about 120 - 
$150 \mathrm{pN}$ (Figure 4c). For higher pulling rates, the maximum was more pronounced with a value of $120-150 \mathrm{pN}$ reached at neutral $\mathrm{pH}$, similarly to the situation at lower elongation rates (Figure 4d). For $\mathrm{pH}$ higher than 8 , weak ruptures forces are in line with a significant extension of the structures. For $\mathrm{pH}$ lower than 6 , rupture forces are weak and they correspond to a minimal extension of the structures (Figures $4 \mathbf{a}$ and $\mathbf{4 b}$ ).

We investigated in more details the dependence of the rupture forces between $\mathrm{Ag} 43$ proteins on pulling rate (Figure 5). Over the whole range of $\mathrm{pH}$ conditions tested, we observed a belllike dependence of the rupture force on pulling rate. Under the three $\mathrm{pH}$ conditions reported in Figure 5, the rupture forces gradually increased from $80-120 \mathrm{pN}$ to a maximum value in the range $150-220 \mathrm{pN}$ at a critical pulling rate in the range of $400-800 \mathrm{~nm} / \mathrm{s}$, and finally it somewhat decreased upon further increase of the pulling rate. This surprising feature was detected for $\mathrm{pH}$ values in the range 3 to 9 , even though the bell-like dependence seems to be less pronounced at $\mathrm{pH}$ 9.2. A three-dimensional representation of the dependence of the rupture forces on $\mathrm{pH}$ and pulling rate, as given in Figure $\mathbf{S 7}$, can be fitted by a 3D-Gaussian form in order to estimate the $\mathrm{pH}$ and pulling rate conditions that are most favorable for strong Ag43 association. We found that these conditions correspond to a $\mathrm{pH}$ of about 7.6 and a pulling rate of $473 \mathrm{~nm} / \mathrm{s}$. The increase of the binding force between the self-associated adhesins with increasing the pulling rate is fully in line with a "catch-bond"-like mechanism where the receptor-ligand interaction is enhanced with increasing tensile mechanical force.

\section{Macroscopic signature of Ag43-Ag43 assembly and pH dependence.}

In order to evaluate the relevance - at a macroscopic scale - of the observed impact of solution $\mathrm{pH}$ on the self-association of Ag43 adhesins, we performed aggregation measurements over the $\mathrm{pH}$ range 3 to 9 on bacterial cells (E. coli - E2498) constitutively expressing or not the Ag43 adhesin. We report in Figure 6 the optical density ratio $\mathrm{OD} / \mathrm{OD}_{0}$ that reflects the 
fraction of non-aggregated (and non-settled) bacterial cells in solution. After 60 minutes, the $\mathrm{OD} / \mathrm{OD}_{0}$ ratio followed a marked parabola-shaped trend versus $\mathrm{pH}$, with a pronounced minimum at $\mathrm{pH} \sim 5$. After 120 and 180 minutes, the parabolic trend became strongly attenuated but a minimum in the $\mathrm{OD} / \mathrm{OD}_{0}$ ratio remains still clearly distinguishable at $\mathrm{pH}$. In line with previous work from our group, ${ }^{33}$ we verified that the $\mathrm{OD} / \mathrm{OD}_{0}$ ratio for the control strain (E2152) lacking the Ag43 proteins at the surface is about 1 over the time period tested in Figure 6 regardless of the $\mathrm{pH}$ conditions The minimum in $\mathrm{OD} / \mathrm{OD}_{0}$ ratio observed for the E2498 strain should thus correspond to an optimum in aggregation as mediated by the selfassociation of Ag43 adhesins located on the surface of the interacting cells. In agreement with Figure 6, self-association of $\mathrm{Ag} 43$ (and therefore bacterial aggregation) is expected to be most significant at $\mathrm{pH}$ values close to the theoretical isoelectric point $\mathrm{pI}=4.83$ of the $\mathrm{Ag} 43 \alpha-$ domain (calculated using http://web.expasy.org/compute_pi/). A mechanistic understanding of these results requires a molecular analysis of the $\mathrm{Ag} 43$ adhesins self-association modes as revealed by force spectroscopy experiments (see Discussion section). It is stressed that macroscopic measurements of the electrohydrodynamic features of bacterial cell walls ${ }^{40}$ are not informative in that respect, as thoroughly detailed in ESI (Figure S8).

\section{Discussion}

The mechanical properties of bacterial adhesins play essential roles in several biophysical and interfacial processes, such as adhesion to abiotic or host cell surfaces, ${ }^{41}$ biofilm formation, ${ }^{16}$, 42-45 auto-aggregation and pathogenicity. ${ }^{19,}$ 46, 47 The combination of single-molecule force (SMFS) and dynamic force spectroscopies (DFS) makes it possible to address the molecular mechanisms underpinning how pathogens surface proteins contribute to host cell recognition, adhesion and infection and how processes including catch bond effect, ${ }^{48}$ unfolding, ${ }^{49}$ unzipping, ${ }^{50}$ and nanospring behavior ${ }^{58}$ come into play. Our results provided the first dynamic 
and biomechanical investigation of Ag43 self-association modes under different $\mathrm{pH}$ and applied shear force conditions.

\section{Mechanical behavior of Ag43 self-association}

Force spectroscopy measurements are in line with the previously reported $\beta$-helix structure of the Ag43 $\alpha$ domain $^{14}$ essentially because our data support that Ag43 $\alpha$ unfolding is sequential and the magnitude of the unfolding forces is in the range of $100-250 \mathrm{pN}^{38}$ The latter well agrees with that given for homophilic association of BCMA0224, a prototypic trimeric autotransporter from B. cenocepacia, and HBHA from M. tuberculosis. ${ }^{29,51}$ The here-reported unfolding forces are also within the same range of those measured for the unfolding of single adhesins such as LapA from $P$. fluorescens and FHA from $H$. influenza. ${ }^{49,}{ }^{52}$ Interestingly, homophilic interactions of adhesins appear stronger (4- to 8-fold) than the interactions between fimbrial adhesins and their corresponding sugar ligands. Forces between 30 to $50 \mathrm{pN}$ have been reported for such fimbrial adhesins/sugar interactions. ${ }^{31,53-55}$

A sequential unfolding of non-fimbrial adhesins reflects the presence of several structural domains such as those recently reported for the FHA protein from $H$. influenzae. ${ }^{49}$ In the case of $\operatorname{Ag} 43 \alpha$, depending on the adopted pulling rate value, we demonstrated the presence of 3 to 10 structural domains that correspond to the number of rupture events detected in the force curves. Heras et al demonstrated that the Ag43a domain of Ag43a in uropathogenic E. coli strain CFT073 exhibits a L-shaped structure consisting of a 13-rung parallel $\beta$-helix domain, followed by three rungs that bend the protein by about $110^{\circ}$ and a C-terminal seven-rung parallel $\beta$-helix domain. ${ }^{14}$ In this structure, 3 domains can be identified and could be further visualized from structure modeling of Ag43 $\alpha$ in E. coli K-12 (see Figure S2): the first of these domains consists of 13 turns of 292 amino acids (green ribbon), the second contains 3 turns of 69 amino acids (red ribbon) and the last domain is composed of 7 turns in a sequence 
of 137 amino acids (yellow ribbon) (see Figure S2). Our AFM data therefore suggest that these 3 domains contain sub-structures that are composed of several turns and that constitute independent structural segments.

The analysis of force experiments performed with increasing pulling rate revealed a catchbond-like behavior of $\mathrm{Ag} 43 \alpha$. Indeed, a rise in the rupture forces from 120 up to $220 \mathrm{pN}$ has been measured at $\mathrm{pH} 7.4$ when the pulling rate was increased from 100 up to $1000 \mathrm{~nm} / \mathrm{s}$ (Figure 4 and Figure 5). In literature, "catch bond" has already been described for fimbrial adhesins (type 1, F1C and P) with an increase of the force from $30 \mathrm{pN}$ up to $70 \mathrm{pN}$ for pulling rate values in the range of 100 to $10000 \mathrm{~nm} / \mathrm{s} .{ }^{56}$ Catch bonds may correspond to several mechanisms allowing the bond lifetime to increase with mechanical stress until a critical shear force condition is reached. Such mechanisms confer bacteria the ability to roll under low shear forces and to strongly adhere at higher shear forces, as in e.g. urinary flows. In our experiments, the $80 \%$ increase in the magnitude of the rupture forces between two $\operatorname{Ag} 43 \alpha$ with increasing pulling rate from 100 to $1000 \mathrm{~nm} / \mathrm{s}$ is well in agreement with that measured for the $\mathrm{P}$ pili from uropathogenic E. coli. ${ }^{57,58}$ This result basically indicates that autoaggregation and adhesion of the bacteria expressing Ag43 onto Ag43-coated surfaces would be favored with increasing flow rates. Even though the molecular mechanism remains quite unclear, we think that the strong pulling rate-dependence of the adhesion force between $\operatorname{Ag} 43 \alpha$ is a signature of catch-bond effects. This effect observed for the self-association of $\mathrm{Ag} 43 \alpha$ domains is maximum at $\mathrm{pH} 7.4$ and is strongly reduced under both low and high $\mathrm{pH}$ conditions (Figure S7, Figures $\mathbf{4 c , d}$ ). Interestingly, this $\mathrm{pH}$ value where the rupture force is maximum roughly identifies with that where the curve maximal extension $L_{\max }$ versus $\mathrm{pH}$ exhibits an inflection point (Figures 4a,b). Overall, these results firmly demonstrate that the auto-assembly of Ag43 proteins is of a dynamic nature and that it depends on solution $\mathrm{pH}$. 
Is the formation of self-associated Ag43 adhesins mediated by trans- and/or cisinteractions?

Heras et al. have clearly identified 2 loop regions (depicted in Figure S2 in pink and blue colors) corresponding to the so-called 1 and 1 ' interfaces recognized as the molecular promoters of self-recognition mechanism. ${ }^{14}$ These authors further stated that self-association of two $\mathrm{Ag} 43 \alpha$ domains takes place through the interfaces 1 and 1' in trans head-to-tail interaction acting like a molecular Velcro (Figure 8). Considering such an interaction configuration via the interfaces 1 and 1', we estimated that the maximal extension before rupture would correspond to the unfolding of the 22 amino acids sequence located before interface 1 and/or the 66 amino acids sequence located between interfaces 1 and 1', as schematized in Figure 8. The concomitant stretching of two 22 amino acids sequences located on both sides of interfaces 1 and 1' is also possible. Such molecular conformations should lead to maximal molecular extensions of 7, 14, 24 and $38 \mathrm{~nm}$ (Figure 8). The first and third values stem from the unfolding of only one $\mathrm{Ag} 43$ protein. The concomitant unfolding of the two 22 amino acid sequences would lead to $7+7=14 \mathrm{~nm}$ (in the case where the sequence between 1 and 1' interfaces is not unfolded) or to a maximal extension of $7+22+7=38 \mathrm{~nm}$ (in the case where the entire sequence along the stem of the L-shaped structure is unfolded). The unfolding mechanisms schemed in Figure 8 result in maximal molecular extensions that are in line with those collected in Figure 4 at sufficiently low pH values and low pulling rates (typically $100 \mathrm{~nm} / \mathrm{s}$, Figure 4a). This strongly suggests the occurrence of trans-association of Ag43 $\alpha$ domains under such $\mathrm{pH}$ and pulling rate conditions.

For $\mathrm{pH}$ values higher than 7 and pulling rates larger than say $400 \mathrm{~nm} / \mathrm{s}$, we systemically observed a maximal extension up to $150 \mathrm{~nm}$ for the interacting Ag43 $\alpha$ domains (Figure 4). One could argue that such large extension could be achieved from the cascade disruption of 
several trans-associated Ag43, in a manner similar to that observed for the autotransporter SAAT adhesin Hap from H. influenzae. ${ }^{22}$ However, a cascade stacking of Ag43 is not possible because, unlike Hap which is a straight solenoid, Ag43 exhibits a bend that necessarily leads to strong steric hindering of the access to the interfaces 1 and 1'. Therefore, in order to explain values as large as $150 \mathrm{~nm}$ for the maximal extension of $\mathrm{Ag} 43 \alpha$ domains (Figure 4), it is mandatory to argue another possible configuration for $\operatorname{Ag} 43 \alpha$ homophilic association, i.e. a configuration other than that previously reported from crystallography analyses. ${ }^{14}$ We suggest that Ag43 $\alpha$ interactions via the interfaces 1 and 1 ' following transassociation predominate at low to intermediate pulling rates and/or low $\mathrm{pH}$ (see discussion above) with as a result a moderate extension of the structure (ca $38 \mathrm{~nm}$ at the largest, Figure 4).

Since molecular extension above $38 \mathrm{~nm}$ cannot result from stretching of Ag43 associated according to trans-interactions, another type of interactions explaining the large molecular extensions observed at large pulling rate (Figure $4 \mathbf{b}$ ) and to some extent at large $\mathrm{pH}$ values should exist. As further discussed in this section, we hypothesize that such interaction between $\mathrm{Ag} 43 \alpha$ is faster and weaker than the trans-interaction detected under low pulling rate conditions. In literature, it is reported that some proteins (Als5p adhesin from C. albicans ${ }^{59,60}$, Nectin proteins $^{61}$ ) may associate side-by-side in cis-configuration. If adopting such a configuration for $\operatorname{Ag} 43 \alpha$ dimers where the bends of the L-shaped proteins are in opposite direction (Figure 9a) and further considering the sole unfolding of one out of the two interacting molecules, it can be estimated that the maximal extension expected should be around $105 \mathrm{~nm}$ (corresponding to 292 amino-acids). In the case where the bends of the Lshaped proteins are in the same direction (Figure 9b), the maximal extension is around 160 $\mathrm{nm}$ (corresponding to 499 amino-acids). Both values 105 and $160 \mathrm{~nm}$ obtained from such unfolding mechanisms very well correspond to the maximal extensions measured by AFM at 
sufficiently large $\mathrm{pH}$ values and/or large pulling rates (Figure 4 and Figure S7). To the best of our knowledge, cis-interactions have never been invoked for autotransporter adhesins for which self-assemblies are deemed to take place only from trans-interactions. ${ }^{14,22}$ Our results do support the occurrence of such interaction configuration. With regard to the continuous increase in maximal molecular extension with increasing $\mathrm{pH}$ and/or pulling rate (Figure $\mathbf{S 7 b}$ ), it can be argued that trans-interactions are predominant at $\mathrm{pH}<7$ and pulling rates lower than $400 \mathrm{~nm} / \mathrm{s}$ and that they lead to moderate maximal extension of the structure. Conversely, cisinteractions are probably the major mode of protein association at $\mathrm{pH}>7$ and at pulling rates larger than $400 \mathrm{~nm} / \mathrm{s}$, and they are in line with molecular extensions that are significantly larger than those obtained according to trans-interactions mode. The $\mathrm{pH}$ and pulling rate regimes where cis- and trans-interactions are most significant are schematized in blue and red-orange color mapping in Figure S7b. The buffer space defined by the green area in Figure S7b can be associated with the overlap between trans- and cis-interaction zones of influence. This coexistence of cis-and trans-interactions as well as the values obtained for $N_{1}$ ( $>400$ amino acids) suggests a possible multimerization where two or more Ag43 $\alpha$ molecules are involved within the molecular assembly and subsequent unfolding upon retraction of the modified tip. For the sake of example, a tetrameric structure of $\mathrm{Ag} 43 \alpha$ is possible through the trans-interaction between two adhesins dimers associated via cis-interactions (Figure 10). Such molecular configuration is also supported by nanogold particles-mediated observations (Figure 1a) that revealed the occurrence of large structures of $c a .200 \mathrm{~nm}$, which probably corresponds to large complexes consisting of more than two Ag43 $\alpha$ molecules.

\section{Building mechanism and unfolding of $\mathrm{Ag} 43 \alpha$ tetrameric structure}

Multimerization of adhesins has been largely documented in literature and particularly for autotransporter adhesins such as Hap from Haemophilus influenzae, AidA-I from Escherichia 
coli and YapC from Yersinia pestis. ${ }^{62,63}$ In addition, the formation of homo-tetramers starting from homo-dimers has been reported for the repair protein MutS from Escherichia $\operatorname{coli}^{64}$ and also for the autotransporter adhesin BadA from Bartonella henselae. ${ }^{65,66}$ The authors stated the existence of equilibrium between dimers and tetramers and the necessity of full-length dimers interactions to achieve the tetramer formation. ${ }^{64}$ The analysis of the modulation of the number of monomers and the maximal extension $L_{\max }$ (Figure 3 and Figure 4, respectively) evidenced that molecular unfolding is quasi-completed (i.e. $L_{\max } \sim 160 \mathrm{~nm}$ ) under restricted range of $\mathrm{pH}$ and pulling rates ( $\mathrm{pH} \sim 9$ and pulling rate $v>1600 \mathrm{~nm} / \mathrm{s}$, cf. Figure S7b) where cis interactions are predominant (Figure 9). Under such extreme ranges of $\mathrm{pH}$ and pulling rates, trans-interactions cannot take place since, in such a configuration, the only stem of the L-shaped structure of Ag43 can be unfolded leading to $L_{\max } \sim 38 \mathrm{~nm}$ at most, in contrast to experimental data. In order to explain the continuous increase of $L_{\max }$ from $\sim 30 \mathrm{~nm}$ to $\sim 160$ $\mathrm{nm}$ with increasing $\mathrm{pH}$ from 3 to 9 and/or pulling rate from $100 \mathrm{~nm} / \mathrm{s}$ to $3200 \mathrm{~nm} / \mathrm{s}$, configurations intermediate between those corresponding to trans and cis interactions or combinations thereof must be envisaged. Such combinations of trans and cis interactions can lead to multimers-assemblies for Ag43, as reported for e.g. MutS and BadA adhesins. ${ }^{64-66}$ In this situation, Ag43 dimers are formed by cis-interactions with the bends of the L-shaped structures in the opposite direction before interacting via interfaces 1 and 1 ' in a transconformation to finally achieve a tetrameric structure (Figure 10). The occurrence of such a structure is in line with the presence of free $\operatorname{Ag} 43 \alpha$ molecules in excess in the solution used for surface functionalization. These free molecules can indeed form dimers with the $\operatorname{Ag} 43 \alpha$ molecules attached to the gold-surface or to the AFM tip by virtue of rapid cis interaction. As discussed below, stretching of the above tetrameric structure can lead to molecular extensions between $30 \mathrm{~nm}$ and $210 \mathrm{~nm}$, in line with extensions data collected in Figure 4. 
The analysis of the force curves collected in the $\mathrm{pH}$ range 4 to 9 evidenced a strong correlation between the $\mathrm{pH}$-dependent maximal unfolding of the self-associated adhesins and the corresponding rupture force (Figure 4). Indeed, a systematic increase of the maximal molecular unwinding was observed with increasing $\mathrm{pH}$ from $\sim 7$ to 9 , i.e. in the $\mathrm{pH}$ range where a maximum in the rupture forces was detected. The theoretical isoelectric points of the interfaces 1 and 1' (involved in the sole trans interactions) can be estimated from a proper account of the amino acids constituting these interaction regions between two sets of residues in each monomer (see Figure S2), with, as result, a theoretical value of 7.10. This value is close to that obtained from AFM rupture force measurements. It thus strongly suggests that this maximum in rupture force between the Ag43 adhesins is predominantly governed by the trans-interactions and to a lower extent by the cis interactions (that come into play at larger $\mathrm{pH}$ values). The existence of two plateau regimes for the maximal molecular extension, i.e. at sufficiently low and large $\mathrm{pH}$ values, may be further explained as follows. The low molecular extension value observed under acidic conditions could originate from the favored formation of H-bonds between the $\beta$-helices. This would necessarily increase the intra-molecular cohesion forces within the $\beta$-helices interacting in trans-conformation and thus reduce the stretchability of the formed dimer. The high molecular extension observed under alkaline conditions could stem from an increase of the electrostatic charges located in the $\beta$-helices. The subsequent increase in the repulsive interactions could enhance the dimer flexibility and thus increase its stretchability as compared to the low $\mathrm{pH}$ situation. Finally, the increase in the rupture forces with $\mathrm{pH}$ could be a signature of the abundance of self-associated $\beta$-helices or a signature of the switch from trans- to $c i s$-interactions for a given dimer.

The results obtained for the maximal molecular extensions and the coexistence of cis- and trans- interactions support the existence of possible multimerization of Ag43 adhesins. The formation of a tetrameric structure composed of only $\operatorname{Ag} 43 \alpha$ adhesins and its unfolding are 
possible only on the premise that cis-interactions are weaker with a shorter life-time (i.e. accessible at large pulling rate or fast pulling dynamics) than trans-interactions that are stronger but with a longer life-time (slow dynamics). In view of the respective magnitude of the cis and trans interactions, the stretching of the tetramer leads to the unfolding of the dimers till breaking of the trans-interaction is reached. In that situation, molecular extensions between $30 \mathrm{~nm}$ and $210 \mathrm{~nm}$ may be achieved, as illustrated in Figure 10. Interestingly, our results suggest that $\operatorname{Ag} 43 \alpha$ may have the properties of promoting -by cis-interaction- the gathering of two or more Ag43 molecules within the E. coli membrane (see Figure 7) favoring subsequent tetramers or higher-order oligomers formation between Ag43 molecules from different bacteria. This is derived from the observation of large nanogold assemblies ( $200 \mathrm{~nm}$ ) on cell membrane surface (Figure 1a). The presence of such multimeric structures promotes efficient aggregation of bacteria.

Our study illustrates how molecular effects can be correlated to macro-scale observations such as aggregation of bacteria constitutively producing Ag43 (Figure 6). The maximum in the interaction forces measured between Ag43 adhesins by SMFS is at $\mathrm{pH}$ close to 7, whereas we observed a faster bacterial aggregation at $\mathrm{pH} 5$ as previously described in the literature (Figure 6). ${ }^{11,67,68}$ This discrepancy could originate from the difference in processes probed at the nanoscale by SMFS and at the macroscopic scale in bacteria aggregation assays. The number of Ag43 molecules involved in self-association process in both situations is probably different since SMFS measurements are related to the detection of single molecules interactions while aggregation of bacteria may be the result of multiple interactions between $\mathrm{Ag} 43 \alpha$ present at the cell surfaces of several E. coli cells. In the latter situation, $\mathrm{pH}$-dependent interactions other than those stemming from the sole Ag43 surely mediate the rate of approach between the cells whose surface is the location of numerous other types of charged ionogenic groups. 


\section{Conclusions}

In this study, the dynamics and $\mathrm{pH}$-dependence of homomeric interactions between $\mathrm{Ag} 43$ adhesins is investigated, recalling that this protein is involved in biofilm formation and bacterial persistence mechanism. Our results support that Ag43 self-association is driven by trans-interactions as originally proposed by Heras et al. In addition, we evidenced the existence of cis-interactions that lead to the formation of Ag43 dimers and tetramers. Results further strongly suggest a coexistence of such cis-and trans-interactions in vivo. Both interactions types are expected to mediate the dynamics of Ag43 complexes formation at the surface of $E$. coli and to strengthen/enhance self-recognition interactions between bacteria. Finally, force spectroscopy experiments highlighted that Ag43 molecules have a high stretchability, and that their self-association dynamics is strongly impacted by environmental factors such as $\mathrm{pH}$ and magnitude of shear forces.

\section{Materials and Methods}

\section{Bacterial strains}

The E. coli K-12 strains used in this study are listed in Table $\mathbf{1}$ where relevant information on their respective construction, antibiotic resistance, genotype and expression of surface appendages can be found. These isogenic strains were constructed from Escherichia coli MG1655 (E. coli genetic stock center CGSC\#6300). All strains used in this study contain the gfpmut3 gene linked to the bla ampicillin resistance gene $\left(a m p^{\mathrm{R}}, 100 \mu \mathrm{g} / \mathrm{ml}\right)$ that makes them fluorescent, and a deletion of the fliE to fliR genes replaced by the cat chloramphenicol resistance gene $\left(\mathrm{cm}^{\mathrm{R}}, 25 \mu \mathrm{g} / \mathrm{ml}\right)$. Our reference strain (E2152) has been additionally deleted for both the fim operon encoding type 1 fimbriae $\left(\Delta f i m A-H:: z e o, z e o^{\mathrm{R}} 50 \mu \mathrm{g} / \mathrm{ml}\right)$ and the agn43 gene $\left(\Delta f l u:: k m, \mathrm{~km}^{\mathrm{R}} 50 \mu \mathrm{g} / \mathrm{ml}\right)$ while strain E2498 constitutively expresses the agn43 gene 
$\left.\left(k m P c L f l u, k m^{\mathrm{R}} 50 \mu \mathrm{g} / \mathrm{ml}\right)\right) .{ }^{32,43,69}$

\section{Growth conditions and preparation for AFM experiments}

Bacteria were pre-grown overnight at $37^{\circ} \mathrm{C}$ under agitation $(150 \mathrm{rpm})$ in $\mathrm{M} 63 \mathrm{~B} 1 \mathrm{minimal}$ medium supplemented with $0.4 \%$ glucose (M63B1glu) and the appropriate antibiotic to select the strain of interest. The following day, fresh M63B1glu medium was inoculated with the overnight culture to an $\mathrm{OD}_{600}$ of ca 0.05 and cultivated under the same conditions until the biomass reached an $\mathrm{OD}_{600}$ of $0.5-0.6$. Then, $2 \mathrm{~mL}$ of the bacterial suspension were removed and placed on a PEI-silicon wafer slide for 30 minutes. The samples were extensively rinsed with PBS solution to remove M63B1glu and placed directly into the AFM closed fluid-cell with $2 \mathrm{~mL}$ of PBS solution at the desired $\mathrm{pH}$ in the range 3 to 10 .

\section{Preparation of His-Tag Ag43 $\alpha$ domains}

The strain producing 6x-His-Tag Ag43 was constructed using $\lambda$-red linear DNA gene inactivation method with help of long primers ${ }^{70,71}$ followed by P1vir transduction. The $6 \mathrm{x}-$ His-tag was introduced 6 amino-acids after the sequence signal cleavage site of Ag43 in the strain TG using as a template the strain MG1655kmPcLflu constitutively expressing Ag43 to create TG_kmPcLflu-His. ${ }^{43}$ We used the following primers to perform the construction:

- Ag43.500-5 5-gtttaccggtgcggtggaccggatatttg-3

- His-tag_alpha.L5 5-gtgcatcatcatcatcatcatcacccgggagaaaccgtgaacggegg-3

- Ag43.ATG+500-3 5-ggcttgacgacctgccagccettat-3

- His-tag_alpha.L3 5-ggtgatgatgatgatgatgatgcacaacgatgtcagcagccagcac-3.

Purification of the His-tagged $\alpha$-domain of Ag43 was performed as follows: 2L culture was grown during $16 \mathrm{~h}$ in $\mathrm{LB}$ medium at $37^{\circ} \mathrm{C}$. Cells were harvested by low centrifugation and washed in $50 \mathrm{~mL} 0.9 \% \mathrm{NaCl}$, then pelleted and resuspended in $50 \mathrm{~mL} 0.5 \mathrm{mM}$ Tris- $\mathrm{HCl}(\mathrm{pH}$ 7.5), $75 \mathrm{mM} \mathrm{NaCl}$. The $\alpha$-domain of $\mathrm{Ag} 43$ was then released from the bacteria cells by heating at $60^{\circ} \mathrm{C}$ for $30 \mathrm{~min}$ and immediately cooled down on ice for $10 \mathrm{~min}$ prior to 
centrifugation $\left(20 \mathrm{~min}\right.$ at $6000 \mathrm{rpm}-4^{\circ} \mathrm{C}$ ). The detached $\alpha$-domain contained in the supernatant was then purified on Ni-NTA His bind resin from Novagen and eluted with 500 $\mathrm{mM}$ imidazole $(20 \mathrm{mM}$ Tris-HCl-pH $8,0.5 \mathrm{M} \mathrm{NaCl})$. The eluted product was immediately dialyzed over $20 \mathrm{mM}$ Tris-HCl-pH 8 and concentrated up to $1.5 \mathrm{mg} / \mathrm{mL}$ using Amicon Ultra units (30KDa membrane) from Millipore. Functionality of the purified $\alpha$-domain of $6 x-H i s-$ Ag43 used for the functionalization of AFM tips and of Nanogold particles was evaluated by measuring the capacity of the prepared Ag43a solution to inhibit Ag43-mediated autoaggregation of the MG1655 $\operatorname{oxy} R$ Ag43-overproducing strain (Figure S3). Briefly, a 5 $\mathrm{mL}$ culture of MG1655 $\operatorname{oxy} R$ was grown in $\mathrm{LB}$ during $16 \mathrm{~h}$ at $37^{\circ} \mathrm{C}$, and its optical density adjusted to 3. Cells were harvested, washed once with PBS $1 \mathrm{X}$ and finally resuspended either in PBS $1 \mathrm{X}$ or in $50-100 \mu \mathrm{g} / \mathrm{mL}$ BSA or purified $6 \mathrm{x}-$ His-Ag43. The suspensions were transferred in $5 \mathrm{~mL}$ tubes and let to settle at room temperature for $6 \mathrm{~h}$ and $24 \mathrm{~h}$ for imaging. An aliquot of aggregated cells was finally transferred on a microscopy slide and cells were visualized using phase-contrast microscopy.

\section{Bacterial Autoaggregation Assay}

Aggregation assays were performed as previously described. ${ }^{72}$ Bacteria were grown overnight at $37^{\circ} \mathrm{C}$ under agitation $(150 \mathrm{rpm})$ in M63B1glu minimal medium. The optical density of the culture at $600 \mathrm{~nm}(\mathrm{OD} 600)$ was adjusted to 3.0 after centrifugation and resuspension in PBS solution at the desired $\mathrm{pH}$ in the range 3 to $9.3 \mathrm{~mL}$ of each $\mathrm{pH}$-adjusted culture was transferred to $5 \mathrm{~mL}$ hemolysis tubes. These tubes were incubated without agitation at room temperature. The OD600 of the upper part of each standing tube culture was determined after 60,130 and 180 min of settling.

\section{Chemicals and AFM-tip functionalization}


Nickel sulfate $\left(\mathrm{NiSO}_{4}\right)$ and PBS tabs were purchased from Sigma-Aldrich (Sigma Aldrich, Saint-Quentin Fallavier, France), and used as received. NTA-thiols (HS- $\left.\left(\mathrm{CH}_{2}\right)_{11}-\mathrm{EG}_{3}-\mathrm{NTA}\right)$ and $\mathrm{HS}-\left(\mathrm{CH}_{2}\right)_{11}-\mathrm{EG}_{3}-\mathrm{OH}$ thiols were purchased from Prochimia Surfaces (ProChimia Surfaces, Sopot, Poland). PEG linkers were purchased from Hermann Gruber group (Institute of Biophysics, University of Linz, Austria). AFM-tips and gold-coated substrates were chemically modified with Ag43 $\alpha$ using NTA-thiol linkers and His tagged Ag43 $\alpha$ molecules following a procedure previously described ${ }^{73}$ for the detection and uncoiling of $\operatorname{Ag} 43 \alpha$ proteins. Gold tips (NPG-10, Bruker Nano AXS, Palaiseau, France) and gold-coated glass slides were covered by NTA-SAM after overnight incubation in a solution of NTA-thiol 0.1 $\mathrm{mM}$ in ethanol. Then, the tips were rinsed extensively with ethanol, dried with nitrogen and incubated $1 \mathrm{~h}$ in $40 \mathrm{mM} \mathrm{NiSO}_{4}$ in PBS solution. The tips were rinsed with milli-Q water, incubated with (His) ${ }_{6}-\mathrm{Ag} 43 \alpha$ at $0.2 \mathrm{mg} / \mathrm{mL}$ in PBS for $2 \mathrm{~h}$ and then rinsed with PBS and stored at $4^{\circ} \mathrm{C}$.

\section{Nanogold particle functionalization and visualization}

A solution of $600 \mu \mathrm{L}$ of $0.5 \mathrm{mg} / \mathrm{mL}$ purified His-tagged Ag43 $\alpha$ protein diluted in PBS buffer was added to $900 \mu \mathrm{L}$ of Ni-NTA-Nanogold® (Ref \#2082, $5 \mathrm{~nm}$ diameter, Nanoprobes, Inc. New York, USA) at $0.5 \mu \mathrm{M}$ for $60 \mathrm{~min}$ at room temperature. Using a 2-fold molar excess of (His) ${ }_{6}$-Ag43 $\alpha$ significantly prevents aggregation of gold nanoparticles after functionalization. Bacterial samples prepared for AFM imaging were incubated 30 minutes with $200 \mu \mathrm{L}$ of the functionalized nanoparticles solution. Then, the samples were rinsed extensively three times with Milli-Q water to remove excess of nanoparticles and gently dehydrated under nitrogen flow for AFM imaging.

\section{AFM imaging, Single Molecule Force and Dynamic Force Spectroscopy measurements}

AFM images were recorded with a FastScan AFM (Bruker AXS, Palaiseau, France) used in

Peak Force ${ }^{\mathrm{TM}}$ tapping mode. Basically, Peak Force ${ }^{\mathrm{TM}}$ tapping mode performs a very fast force 
curve at every pixel in the image. The peak interaction force in each of these force curves is then used as the imaging feedback signal. Peak Force Tapping mode modulates the Z-piezo at $\sim 2 \mathrm{kHz}$ with a default Peak Force Amplitude of $150 \mathrm{~nm}$ (0-peak). All values above and below this 0-peak magnitude is recorded as a Peak Force Error from which image is constructed. Force-distance curves were recorded using a MFP3D-BIO instrument (Asylum Research Technology, Atomic Force F\&E GmbH, Mannheim, Germany). Conical gold coated AFM-tips were purchased from Bruker (NPG, Bruker AXS, Palaiseau, France) with spring constants of about $120-150 \mathrm{pN} / \mathrm{nm}$. Experiments were performed in PBS at different $\mathrm{pH}$ values $(3,5,7,9$ and 10) and at room temperature. Adhesion forces, conformational characteristics of the adhesins and their dynamic behavior were measured by recording ForceVolume Images (FVI) consisting of a grid of 32-by-32 force curves obtained upon approach and subsequent retraction of the tip (Single Molecule Force Spectroscopy for SMFS experiments) at a loading rate in the range $10^{4}-10^{5} \mathrm{pN} / \mathrm{s}$ (variable retraction speed for DFS experiments).

In the SMFS experiments, the adhesins located on the gold-surfaces and on the biological samples were stretched upon removal of the chemically modified AFM tip away from the surface (see Figure S2). The obtained force versus distance curves were then analyzed on the basis of the WLC (Worm Like Chain) model. This model is the most suitable and frequently used to describe the extension of polypeptides. ${ }^{74,75}$ The extension $z$ of a macromolecule is related to the retraction force $F_{\text {adh }}$ via (eq. 1 ):

$$
F_{\text {adh }}(z)=-\frac{k_{B} T}{l_{p}}\left[\frac{z}{L_{c}}+4\left(1-\frac{z}{L_{c}}\right)^{-2}-\frac{1}{4}\right]
$$

where the persistence length $l_{p}$ is a direct measure of the chain stiffness, $L_{c}$ is the total contour length of the biomacromolecule and $k_{B}$ is the Boltzmann constant. 
The number of monomers in the polypeptide chains was then derived from the following equation (eq.2):

$$
N=\frac{L_{c}}{l_{p}}
$$

All the FVI were analyzed by mean of an automatic Matlab algorithm described elsewhere. ${ }^{39}$

\section{Electronic Supplementary Information (ESI)}

Electronic Supplementary Information (ESI) available: This material is available free of charge via the Internet at http://www.rsc.org/. 


\section{References}

1. R. G. Gerlach and M. Hensel, Int. J. Med. Microbiol., 2007, 297, 401-415.

2. R. Fronzes, H. Remaut and G. Waksman, EMBO J., 2008, 27, 2271-2280.

3. P. Klemm, R. M. Vejborg and O. Sherlock, Int. J. Med. Microbiol., 2006, 296, 187195.

4. J. C. Leo, I. Grin and D. Linke, Philos. Trans. R. Soc. B-Biol. Sci., 2012, 367, 10881101.

5. I. Benz and M. A. Schmidt, Infect. Immun., 1989, 57, 1506-1511.

6. E. A. Elsinghorst and J. A. Weitz, Infect. Immun., 1994, 62, 3463-3471.

7. B. Diderichsen, J. Bacteriol., 1980, 141, 858-867.

8. P. Owen, in Electroimmunochemical analysis of membrane proteins, ed. JB, Elsevier Science Publishing, Inc., Amsterdam, 1983, pp. 347-373.

9. T. J. Wells, M. Totsika and M. A. Schembri, Microbiology-(UK), 2010, 156, 24592469.

10. J. B. Kaper, J. P. Nataro and H. L. T. Mobley, Nat. Rev. Microbiol., 2004, 2, 123-140.

11. P. Klemm, L. Hjerrild, M. Gjermansen and M. A. Schembri, Mol. Microbiol., 2004, 51, 283-296.

12. P. Caffrey and P. Owen, J. Bacteriol., 1989, 171, 3634-3640.

13. M. W. Van der Woude and I. R. Henderson, Annu. Rev. Microbiol., 2008, 62, 153169.

14. B. Heras, M. Totsika, K. M. Peters, J. J. Paxman, C. L. Gee, R. J. Jarrott, M. A. Perugini, A. E. Whitten and M. A. Schembri, Proc Natl Acad Sci. USA, 2014, 111, 457-462.

15. H. Hasman, T. Chakraborty and P. Klemm, J. Bacteriol., 1999, 181, 4834-4841.

16. C. Beloin, A. Roux and J. Ghigo, Curr. Top. Microbiol., 2008, 322, 249-289.

17. P. N. Danese, L. A. Pratt, S. L. Dove and R. Kolter, Mol. Microbiol., 2000, 37, 424432.

18. I. R. Henderson, M. Meehan and P. Owen, in Mechanisms in the Pathogenesis of Enteric Diseases, eds. P. S. Paul, D. H. Francis and D. A. Benfield, 1997, vol. 412, pp. 349-355. 
19. G. C. Ulett, J. Valle, C. Beloin, O. Sherlock, J. M. Ghigo and M. A. Schembri, Infect. Immun., 2007, 75, 3233-3244.

20. G. G. Anderson, J. J. Palermo, J. D. Schilling, R. Roth, J. Heuser and S. J. Hultgren, Science, 2003, 301, 105-107.

21. S. Fexby, T. Bjarnsholt, P. O. Jensen, V. Roos, N. Hoiby, M. Givskov and P. Klemm, Infect. Immun., 2007, 75, 30-34.

22. G. Y. Meng, N. Spahich, R. Kenjale, G. Waksman and J. W. St Geme, EMBO J., 2011, 30, 3864-3874.

23. Y. F. Dufrêne, Nature Reviews: Microbiology, 2004, 2, 451-460.

24. Y. F. Dufrêne, Nat. Protoc., 2008, 3, 1132-1138.

25. G. Francius, S. Lebeer, D. Alsteens, L. Wildling, H. J. Gruber, P. Hols, S. De Keersmaecker, J. Vanderleyden and Y. F. Dufrêne, ACS Nano, 2008, 2, 1921-1929.

26. V. Dupres, D. Alsteens, G. Andre and Y. F. Dufrene, Trends Microbiol., 2010, 18, 397-405.

27. P. Hinterdorfer and Y. F. Dufrêne, Nat. Methods, 2006, 3, 347-355.

28. D. Alsteens, M. C. Garcia, P. N. Lipke and Y. F. Dufrêne, Proc. Natl. Acad. Sci. USA, 2010, 107, 20744-20749.

29. S. El-Kirat-Chatel, D. Mil-Homens, A. Beaussart, A. M. Fialho and Y. F. Dufrêne, Mol. Microbiol., 2013, 89, 649-659.

30. I. E. Ivanov, C. D. Boyd, P. D. Newell, M. E. Schwartz, L. Turnbull, M. S. Johnson, C. B. Whitchurch, G. A. O'Toole and T. A. Camesano, Res. Microbiol., 2012, 163, 685-691.

31. A. Jacquot, C. Sakamoto, A. Razafitianamaharavo, C. Caillet, J. Merlin, A. Fahs, J. M. Ghigo, C. Beloin, J. F. L. Duval and G. Francius, J. Biomed. Nanotechnol., 2014, 10, 3361-3372.

32. G. Francius, P. Polyakov, J. Merlin, Y. Abe, J. M. Ghigo, C. Merlin, C. Beloin and J. F. L. Duval, PLoS One, 2011, 6, e20066.

33. A. Chauhan, C. Sakamoto, J. M. Ghigo and C. Beloin, PLoS One, 2013, 8, e73568.

34. H. Hasman, M. A. Schembri and P. Klemm, J. Bacteriol., 2000, 182, 1089-1095.

35. S. Jain, P. van Ulsen, M. A. Schmidt, R. Fernandez, J. Tommassen and M. B. Goldberg, J. Bacteriol., 2006, 188, 4841-4850.

36. D. Alsteens, V. Dupres, S. A. Klotz, N. K. Gaur, P. N. Lipke and Y. F. Dufrene, ACS Nano, 2009, 3, 1677-1682.

37. J. P. Junker and M. Rief, Proc. Natl. Acad. Sci. USA, 2009, 106, 14361-14366. 
38. M. Rief, J. Pascual, M. Saraste and H. E. Gaub, J. Mol. Biol., 1999, 286, 553-561.

39. P. Polyakov, C. Soussen, J. B. Duan, J. F. L. Duval, D. Brie and G. Francius, PLoS One, 2011, 6, e18887.

40. J. F. L. Duval and F. Gaboriaud, Curr. Opin. Colloid Interface Sci., 2010, 15, 184195.

41. R. J. T. Emerson and T. A. Camesano, Appl. Environ. Microbiol., 2004, 70, 60126022.

42. M. Klausen, A. Heydorn, P. Ragas, L. Lambertsen, A. Aaes-Jorgensen, S. Molin and T. Tolker-Nielsen, Mol. Microbiol., 2003, 48, 1511-1524.

43. S. Da Re, B. Le Quere, J. M. Ghigo and C. Beloin, Appl. Environ. Microbiol., 2007, 73, 3391-3403.

44. $\quad$ N. A. Ledeboer and B. D. Jones, J. Bacteriol., 2005, 187, 3214-3226.

45. K. Jonas, H. Tomenius, A. Kader, S. Normark, U. Romling, L. M. Belova and O. Melefors, BMC Microbiol., 2007, 7, 9.

46. L. Craig, M. E. Pique and J. A. Tainer, Nat. Rev. Microbiol., 2004, 2, 363-378.

47. A. N. Mabbett, G. C. Ulett, R. E. Watts, J. J. Tree, M. Totsika, C. L. Y. Ong, J. M. Wood, W. Monaghan, D. F. Looke, G. R. Nimmo, C. Svanborg and M. A. Schembri, Int. J. Med. Microbiol., 2009, 299, 53-63.

48. P. Aprikian, G. Interlandi, B. A. Kidd, I. Le Trong, V. Tchesnokova, O. Yakovenko, M. J. Whitfield, E. Bullitt, R. E. Stenkamp, W. E. Thomas and E. V. Sokurenko, PLoS Biol., 2011, 9, e1000617.

49. D. Alsteens, N. Martinez, M. Jamin and F. Jacob-Dubuisson, PLoS One, 2013, 8, e73572.

50. D. J. Muller, W. Baumeister and A. Engel, Proc. Natl. Acad. Sci. USA, 1999, 96, $13170-13174$.

51. C. Verbelen, D. Raze, F. Dewitte, C. Locht and Y. F. Dufrene, J. Bacteriol., 2007, 189, 8801-8806.

52. S. El-Kirat-Chatel, A. Beaussart, C. D. Boyd, G. A. O'Toole and Y. F. Dufrêne, ACS Chem. Biol., 2014, 9, 485-494.

53. J. E. Klinth, M. Castelain, B. E. Uhlin and O. Axner, PLoS One, 2012, 7, e38548.

54. M. Castelain, S. Ehlers, J. Klinth, S. Lindberg, M. Andersson, B. E. Uhlin and O. Axner, Eur. Biophys. J. Biophy., 2011, 40, 305-316.

55. M. Castelain, A. E. Sjostrom, E. Fallman, B. E. Uhlin and M. Andersson, Eur. Biophys. J. Biophy., 2010, 39, 1105-1115. 
56. O. Axner, M. Andersson, O. Bjornham, M. Castelain, J. Klinth, E. Koutris and S. Schedin, in Bacterial Adhesion: Chemistry, Biology and Physics, eds. D. Linke and A. Goldman, Springer-Verlag Berlin, Berlin, 2011, vol. 715, pp. 301-313.

57. M. Andersson, E. Fallman, B. E. Uhlin and O. Axner, Biophys. J., 2006, 91, 27172725 .

58. O. Bjornham, H. Nilsson, M. Andersson and S. Schedin, Eur. Biophys. J. Biophy., 2009, 38, 245-254.

59. A. Beaussart, D. Alsteens, S. El-Kirat-Chatel, P. N. Lipke, S. Kucharikova, P. Van Dijck and Y. F. Dufrene, ACS Nano, 2012, 6, 10950-10964.

60. D. Alsteens, A. Beaussart, S. Derclaye, S. El-Kirat-Chatel, H. R. Park, P. N. Lipke and Y. F. Dufrene, Anal Methods, 2013, 5, 3657-3662.

61. O. J. Harrison, J. Vendome, J. Brasch, X. Jin, S. Hong, P. S. Katsamba, G. Ahlsen, R. B. Troyanovsky, S. M. Troyanovsky, B. Honig and L. Shapiro, Nat. Struct. Mol. Biol., 2012, 19, 906-915.

62. A. Lyskowski, J. C. Leo and A. Goldman, Adv. Exp. Med. Biol., 2011, 715, 143-158.

63. S. Felek, M. B. Lawrenz and E. S. Krukonis, Microbiology-(UK), 2008, 154, 18021812.

64. F. S. Groothuizen, A. Fish, M. V. Petoukhov, A. Reumer, L. Manelyte, H. H. K. Winterwerp, M. G. Marinus, J. H. G. Lebbink, D. I. Svergun, P. Friedhoff and T. K. Sixma, Nucleic Acids Res., 2013, 41, 8166-8181.

65. P. O. Kaiser, D. Linke, H. Schwarz, J. C. Leo and V. A. Kempf, Cell. Microbiol., 2012, 14, 198-209.

66. M. D. Hartmann, O. Ridderbusch, K. Zeth, R. Albrecht, O. Testa, D. N. Woolfson, G. Sauer, S. Dunin-Horkawicz, A. N. Lupas and B. H. Alvarez, Proc. Natl. Acad. Sci. USA, 2009, 106, 16950-16955.

67. O. Sherlock, R. M. Vejborg and P. Klemm, Infect. Immun., 2005, 73, 1954-1963.

68. O. Sherlock, M. A. Schembri, A. Reisner and P. Klemm, J. Bacteriol., 2004, 186, 8058-8065.

69. C. G. Korea, R. Badouraly, M. C. Prévost, J. M. Ghigo and C. Beloin, Environ. Microbiol., 2010, 12, 1957-1977.

70. M. K. Chaveroche, J. M. Ghigo and C. d'Enfert, Nucleic Acids Res., 2000, 28, $\mathrm{n}^{\circ} 22 \mathrm{e} 97$.

71. A. Derbise, B. Lesic, D. Dacheux, J. M. Ghigo and E. Carniel, FEMS Immunol. Med. Microbiol., 2003, 38, 113-116.

72. A. Roux, C. Beloin and J. M. Ghigo, J. Bacteriol., 2005, 187, 1001-1013. 
73. V. Duprès, F. D. Menozzi, C. Locht, B. H. Clare, N. L. Abbott, S. Cuenot, C. Bompard, D. Raze and Y. F. Dufrêne, Nat. Methods, 2005, 2, 515-520.

74. H. Wei and T. G. M. van de Ven, Appl. Spectrosc. Rev., 2008, 43, 111-133.

75. F. Rico, A. Rigato, L. Picas and S. Scheuring, J. Nanobiotechnol., 2013, 11, S3.

76. J. M. Ghigo, Nature, 2001, vol. 412, pp. 442-445.

77. J. M. Ghigo, Nature, 2001, 412, 442-445.

78. M. Chaveroche, J. Ghigo and C. d'Enfert, Nucleic Acids Research, 2000, 28, e97.

76 et 77 sont la meme reference !!!!!!!!!!!!!!!!!!!!!!!!!!!!!!! 


\section{TABLES}

Table 1. Strains and plasmids used in this work.

\begin{tabular}{|c|c|c|}
\hline Strain or plasmid & $\begin{array}{l}\text { Relevant genotypic and phenotypic } \\
\text { characteristics }\end{array}$ & $\begin{array}{l}\text { Source or } \\
\text { reference }\end{array}$ \\
\hline \multicolumn{3}{|l|}{ Strains } \\
\hline TG & TG1 cured of the F plasmid, proline auxotroph & 77 \\
\hline MG1655 $\Delta o x y R$ & $\begin{array}{l}\text { MG1655 deleted for } \text { oxyR, constitutive } \\
\text { production of } \mathrm{Ag} 43, \mathrm{Km}^{\mathrm{R}}\end{array}$ & 72 \\
\hline MG1655kmPcLflu & $\begin{array}{l}\text { flu }(\text { agn } 43) \text { gene placed under the control of the } \\
k m \text { PcLrbs cassette } \lambda \mathrm{P}_{\mathrm{R}} \text { promoter, constitutive } \\
\text { Ag43 production, } \mathrm{Km}^{\mathrm{R}}\end{array}$ & 43 \\
\hline TG_kmPcLflu-His & $\begin{array}{l}6 \mathrm{x} \text {-His tag placed } 6 \text { amino-acids after the Ag43 } \\
\text { signal sequence cleavage site in strain TG with } \\
\text { constitutive expression of } f l u(a g n 43), \mathrm{Km}^{\mathrm{R}}\end{array}$ & This study \\
\hline E2152 & $\begin{array}{l}\text { MG1655_gfp__fliE- } \\
R:: c a t \_\Delta f l u:: \mathrm{Km}_{-} \Delta \text { fimAICDFGH::zeo, } \\
\text { GFP+, no flagella, no Ag43 protein, no type } 1 \\
\text { fimbriae, Amp }{ }^{\mathrm{R}}, \mathrm{Cm}^{\mathrm{R}}, \mathrm{Km}^{\mathrm{R}}, \mathrm{Zeo}^{\mathrm{R}}\end{array}$ & 32 \\
\hline E2498 & $\begin{array}{l}\text { MG1655_gfp__fliE- } \\
R:: c a t \_ \text {fimAICDFGH::zeo_kmPcLflu, } \\
\text { GFP+, no flagella, no type } 1 \text { fimbriae, } \\
\text { constitutive Ag43, } \mathrm{Amp}^{\mathrm{R}}, \mathrm{Cm}^{\mathrm{R}}, \mathrm{Km}^{\mathrm{R}}, \mathrm{Zeo}^{\mathrm{R}}\end{array}$ & 32 \\
\hline \multicolumn{3}{|l|}{ Plasmids } \\
\hline pKOBEG & $\begin{array}{l}\text { pSC101 ts (replicates at } 30^{\circ} \mathrm{C} \text { ), araC, arabinose- } \\
\text { inducible } \lambda \text { red } \gamma \beta \alpha \text { operon }, \mathrm{Cm}^{\mathrm{R}}\end{array}$ & 78 \\
\hline
\end{tabular}

\section{Table 2.}

Values of the conformational parameters (number of rupture events per force curve, persistence length, contour length, rupture force and number of monomers) derived from WLC modeling (eq 1) at $\mathrm{pH} 7.4$ for various retraction rates (indicated). Data were extracted from a $5 \mu \mathrm{m} \times 5 \mu \mathrm{m}$ Force Volume Image (FVI) consisting of 1024 force curves recorded at pH 7 over the range of pulling rate $100-3200 \mathrm{~nm} / \mathrm{s}$. The double entries for persistence length, contour length and number of monomers originate from the bimodal distribution issued from 
the statistical analysis of Figure 3 and Figure S4. ${ }^{*}$ corresponds to the average value of $N_{1}$ and $^{* *}$ corresponds to the average value of $N_{2}$. See text for further details.

\begin{tabular}{ccccc}
\hline \multicolumn{5}{c}{ Worm Like Chain model (pH 7.4) } \\
\hline Retraction rate (nm/s) & 100 & 400 & 1600 & 3200 \\
\hline Number of ruptures & $7 \pm 2$ & $7 \pm 3$ & $4 \pm 2$ & $4 \pm 2$ \\
\hline \multirow{2}{*}{ Persistence length (nm) } & $0.04 \pm 0.03$ & $0.07 \pm 0.04$ & $0.07 \pm 0.05$ & $0.04 \pm 0.03$ \\
& $0.15 \pm 0.06$ & $0.16 \pm 0.05$ & $0.15 \pm 0.07$ & $0.13 \pm 0.08$ \\
\hline \multirow{2}{*}{ Contour length (nm) } & $13.71 \pm 5.93$ & $26.75 \pm 13.41$ & $31.03 \pm 17.33$ & $36.25 \pm 11.08$ \\
& $41.09 \pm 21.54$ & $49.31 \pm 19.16$ & $71.45 \pm 22.28$ & $94.67 \pm 19.62$ \\
\hline Rupture forces (pN) & $138 \pm 35$ & $216 \pm 47$ & $211 \pm 82$ & $141 \pm 60$ \\
\hline \multirow{2}{*}{ Number of monomers } & $422 \pm 224^{*}$ & $385 \pm 262^{*}$ & $407 \pm 252^{*}$ & $418 \pm 156^{*}$ \\
& $1465 \pm 272^{* *}$ & $1495 \pm 412^{* *}$ & $1376 \pm 427^{* *}$ & $1938 \pm 711^{* *}$ \\
\hline
\end{tabular}

\section{Table 3.}

Values of the number of monomers derived from WLC modelling (eq 1) for various $\mathrm{pH}$ values at a pulling rate of $400 \mathrm{~nm} / \mathrm{s}$. Data were extracted from a $5 \mu \mathrm{m} \times 5 \mu \mathrm{m}$ Force Volume Image (FVI) consisting of 1024 force curves recorded over a $\mathrm{pH}$ range of 5-9 for a pulling rate of $400 \mathrm{~nm} / \mathrm{s}$.

\begin{tabular}{cccccc}
\hline \multicolumn{5}{c}{ Worm Like Chain model $(\boldsymbol{v}=\mathbf{4 0 0} \mathbf{~ n m} / \mathbf{s})$} \\
\hline $\mathbf{p H}$ & 5.2 & 6.1 & 7.4 & 8.1 & 9.2 \\
\hline $\mathbf{N}_{\mathbf{1}}$ & $338 \pm 207(49)$ & $347 \pm 236(49)$ & $385 \pm 262(49)$ & $341 \pm 216(47)$ & $418 \pm 286(44)$ \\
\hline $\mathbf{N}_{\mathbf{2}}$ & $1495 \pm 242(51)$ & $1621 \pm 293(51)$ & $1495 \pm 412(51)$ & $1493 \pm 403(53)$ & $1638 \pm 711(56)$ \\
\hline
\end{tabular}




\section{List of Figures}

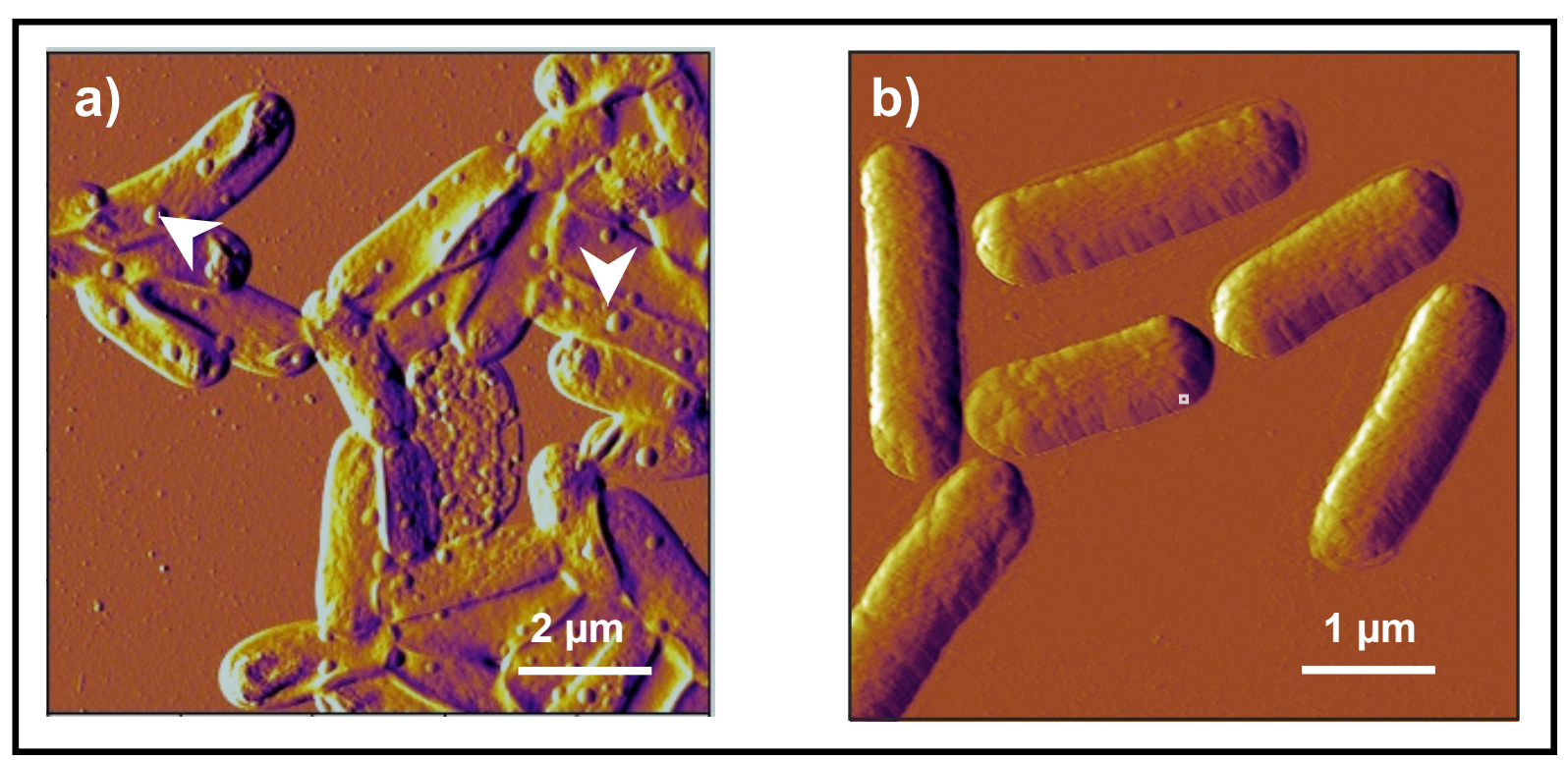

Figure 1. Morphological analyses and nanogold-mediated detection of Ag43 produced by $E$. coli.

Nanogold-mediated detection of cell surface Ag43 by AFM. Images were carried out in air after slight dehydration of the sample. E2498 Ag43 constitutive producer bacterial cells (a) and E2152 non Ag43 producer bacteria (negative control strain) (b) were immobilized onto a PEI coated substrate, exposed for 1 hour to a solution containing Ag43 $\alpha$-functionalized nanogold particles and then extensively rinsed with PBS. 

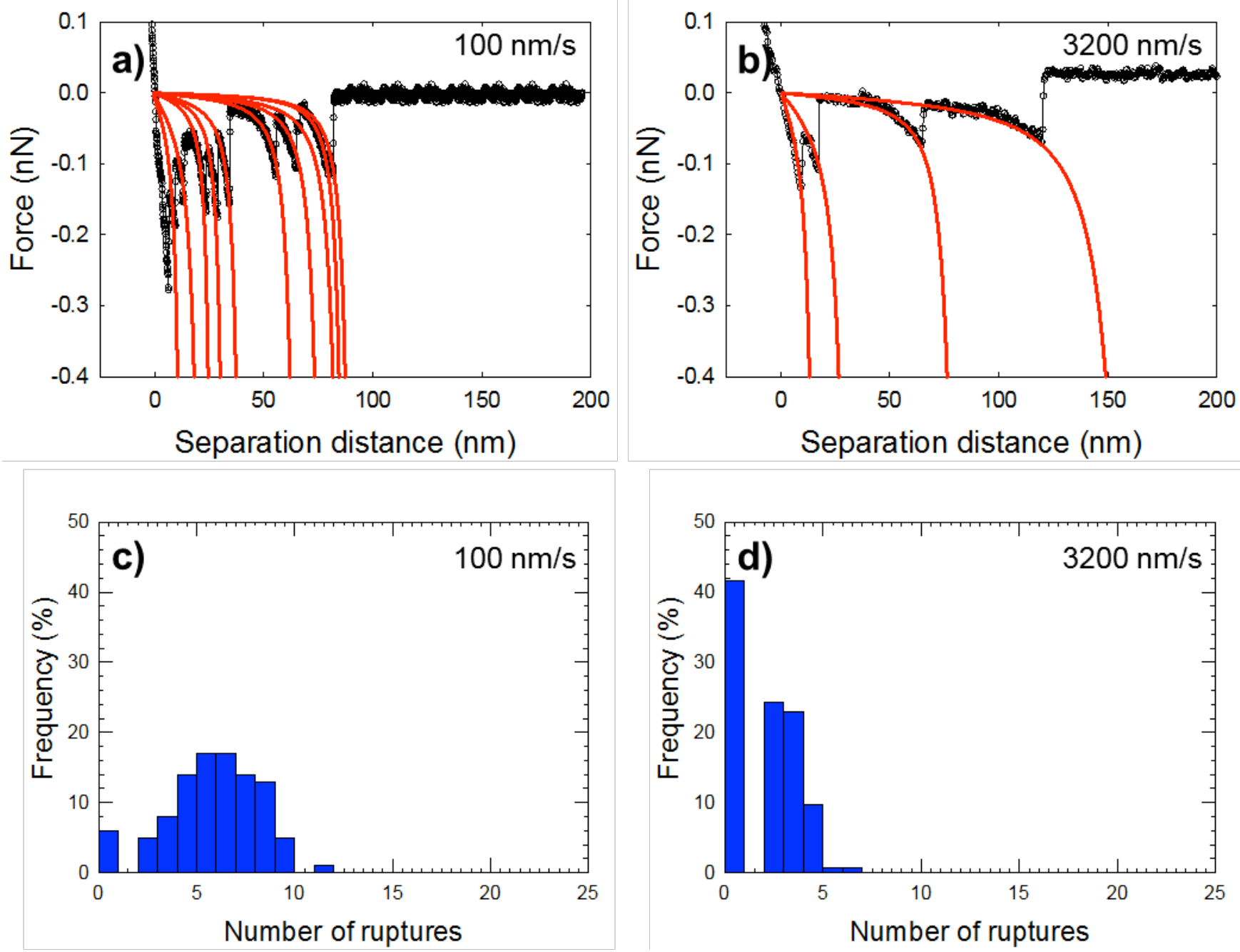

Figure 2. Retraction force curves and statistical analysis of the rupture events.

$(\mathrm{a}, \mathrm{b})$ Typical force-curves corresponding to the molecular unfolding of Ag43 $\alpha$-domains on model gold surfaces for retraction speeds of $100 \mathrm{~nm} / \mathrm{s}$ (panel a) and $3200 \mathrm{~nm} / \mathrm{s}$ (panel b) at $\mathrm{pH}$ 7.4. Black circles correspond to experimental retraction force curves and red lines correspond to WLC theoretical fitting. (c, d) Statistical distribution of the number of ruptures events per force curve for pulling rate of $100 \mathrm{~nm} / \mathrm{s}$ (panel c) and $3200 \mathrm{~nm} / \mathrm{s}$ (panel d) at pH 7.4. 

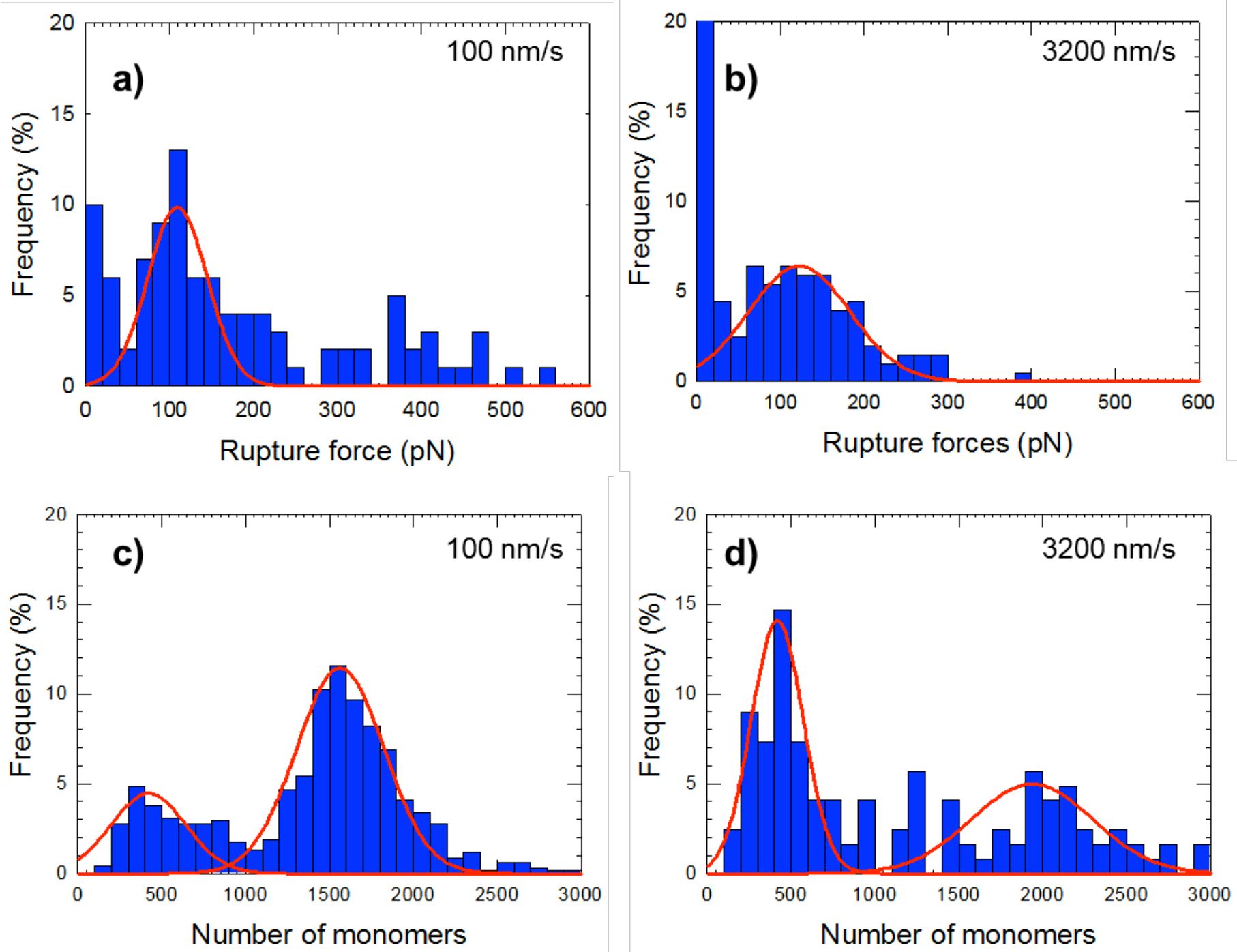

Figure 3. Adhesion forces and statistical analysis from WLC modeling.

$(a, b)$ Statistical distribution of the rupture forces measured between Ag43 $\alpha$-domains for pulling rates of $100 \mathrm{~nm} / \mathrm{s}$ (panel a) and $3200 \mathrm{~nm} / \mathrm{s}$ (panel b) at $\mathrm{pH} \mathrm{7.4.} \mathrm{(c,} \mathrm{d)} \mathrm{Statistical}$ distribution of $N$, the number of monomers detected during the protein unfolding. Values were obtained from WLC modeling of the force curves for pulling rates of $100 \mathrm{~nm} / \mathrm{s}$ (panel c) and $3200 \mathrm{~nm} / \mathrm{s}$ (panel d) at $\mathrm{pH} 7.4$. 

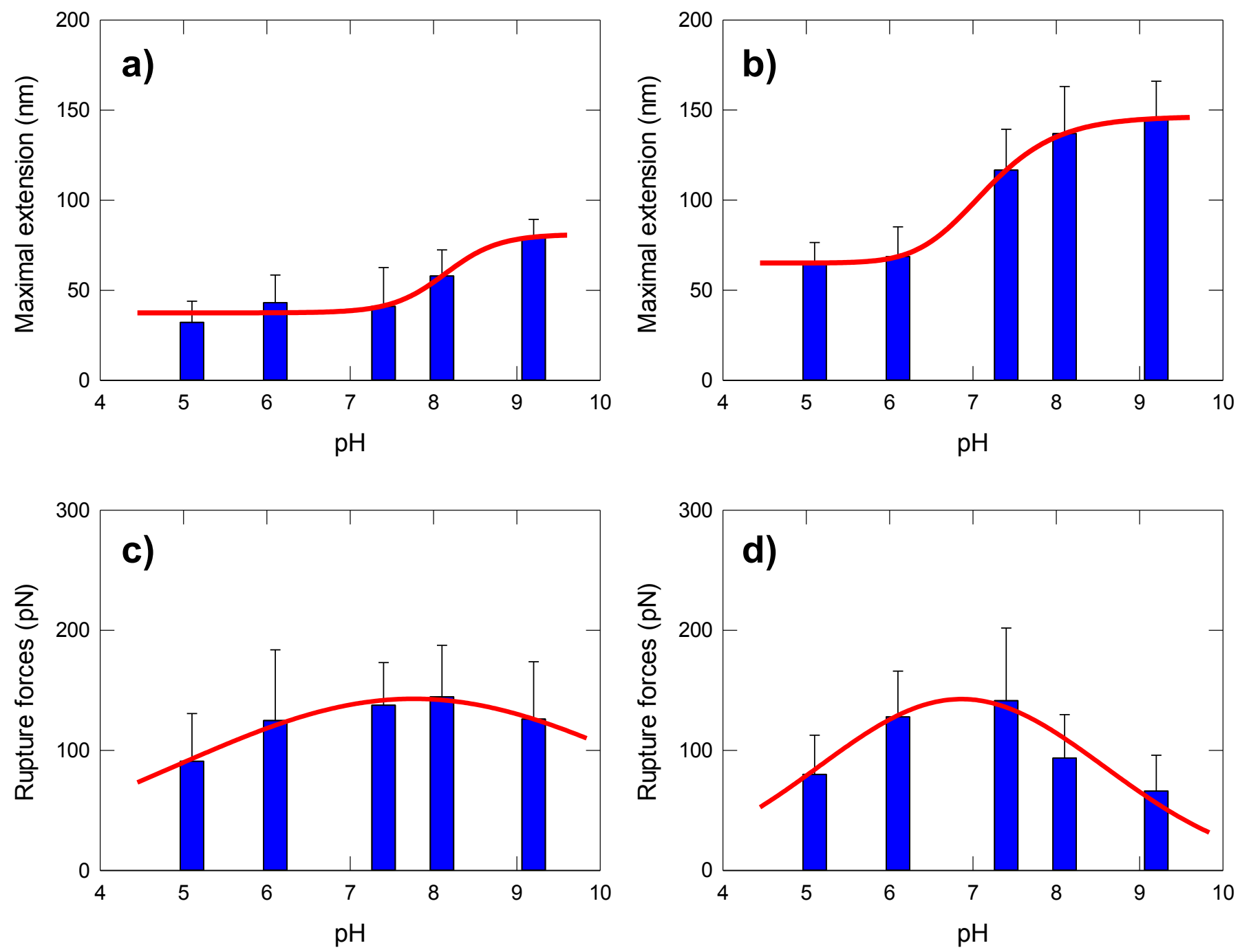

Figure 4. Dependence of the maximal molecular extension and rupture force on solution pH and pulilng rate value.

(a, b) Evolution with $\mathrm{pH}$ of the average maximal molecular extension of Ag43 self-associated adhesins measured by SMFS at $100 \mathrm{~nm} / \mathrm{s}$ (panel a) and $3200 \mathrm{~nm} / \mathrm{s}$ (panel b). The average maximal extensions were calculated from the statistic distributions of the last rupture distances derived from the whole retraction force curves at pulling rates of $100 \mathrm{~nm} / \mathrm{s}$ and 3200 $\mathrm{nm} / \mathrm{s}$. (c, d) Evolution with $\mathrm{pH}$ of the average rupture forces of Ag43 self-associated adhesins measured by SMFS. The average rupture forces were calculated from the whole retraction force curves at pulling rates of $100 \mathrm{~nm} / \mathrm{s}$ (panel c) and $3200 \mathrm{~nm} / \mathrm{s}$ (panel d). 

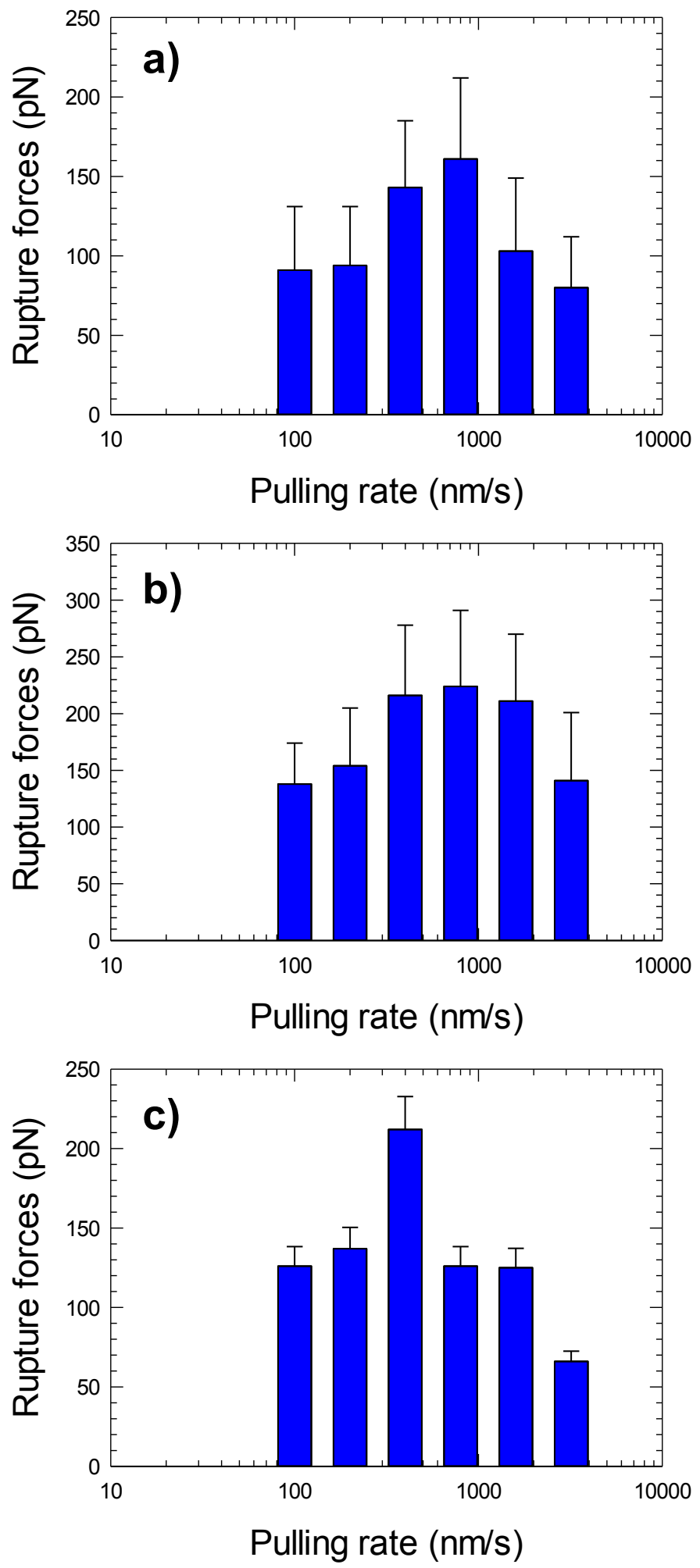

Figure 5. Effect of the solution pH on the catch-bond-like behavior of $\operatorname{Ag43} \alpha$.

Evolution of the rupture forces (dissociation) of self-associated $\operatorname{Ag} 43 \alpha$-domains measured by SMFS as a function of pulling rate at $\mathrm{pH} 5.2(\mathrm{a}), 7.4$ (b) and 9.2 (c). 


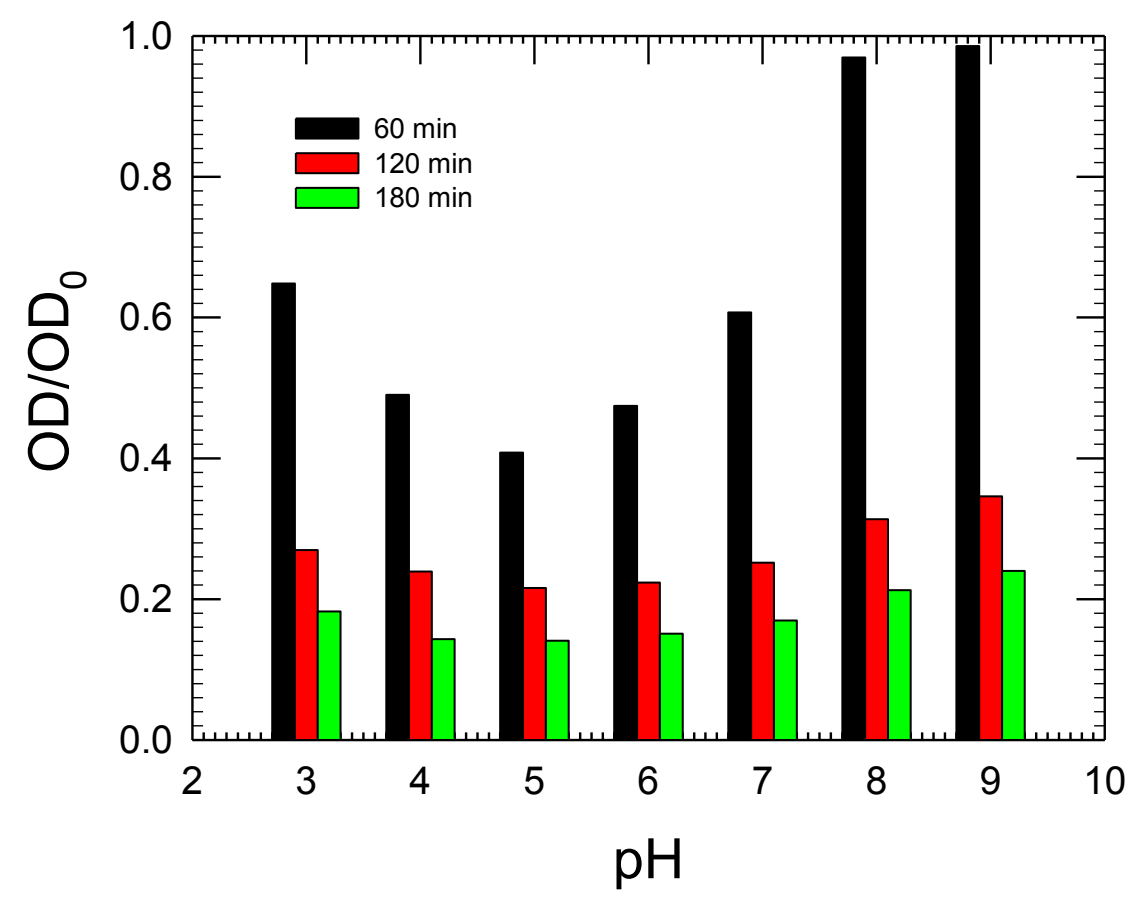

Figure 6. Effect of pH on the kinetics of Ag43-mediated E. coli auto-aggregation.

Auto-aggregation profiles for the E2498 strain performed over the $\mathrm{pH}$ range 3-9. Optical density (OD) values were measured after $60 \mathrm{~min}, 120 \mathrm{~min}$ and $180 \mathrm{~min}$ and normalized by OD values at $t=0$ min. In line with previous work from our group, ${ }^{33}$ we verified that the $\mathrm{OD} / \mathrm{OD}_{0}$ ratio for the control strain (E2152) lacking the Ag43 proteins at the surface is about 1 over the time period tested in Figure 6 regardless of the $\mathrm{pH}$ conditions 

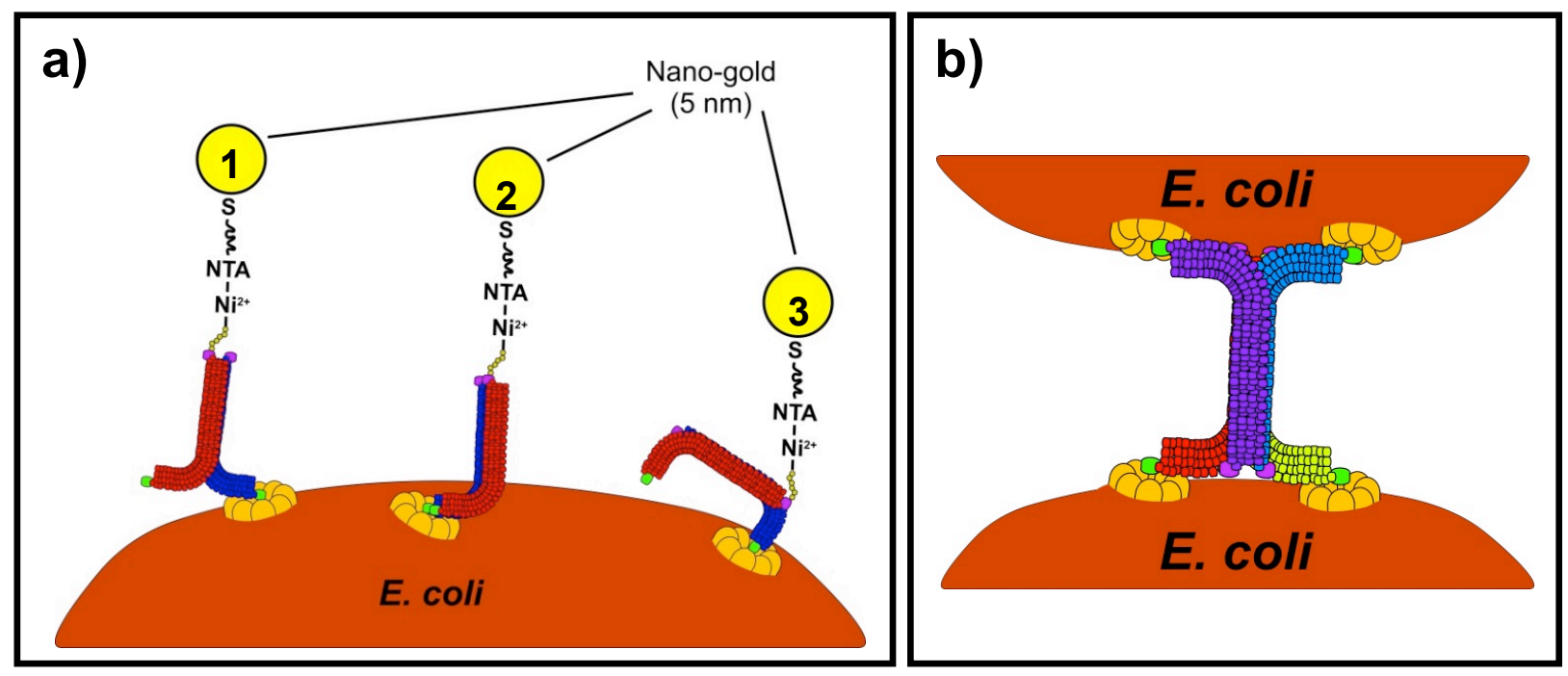

Figure 7. Schematic representation of possible cis- and trans-conformation of adhesins interactions for explaining nanogold detection and SMFS experiments.

Schematic representations of the possible conformations of nanogold particles attached onto bacterial cells (a) and the multiple $\operatorname{Ag} 43 \alpha$ self-association between two bacteria (b). Conformations 1 and 2 correspond to Ag43 $\alpha$ dimerization through cis-interactions (the bends of the L-shaped proteins are either along the same or opposite direction). Conformation 3 illustrates the $\operatorname{Ag} 43 \alpha$ self-association mediated by the trans-interaction (L-shaped adhesins are interacting like a molecular Velcro with a head-to-tail geometry). 


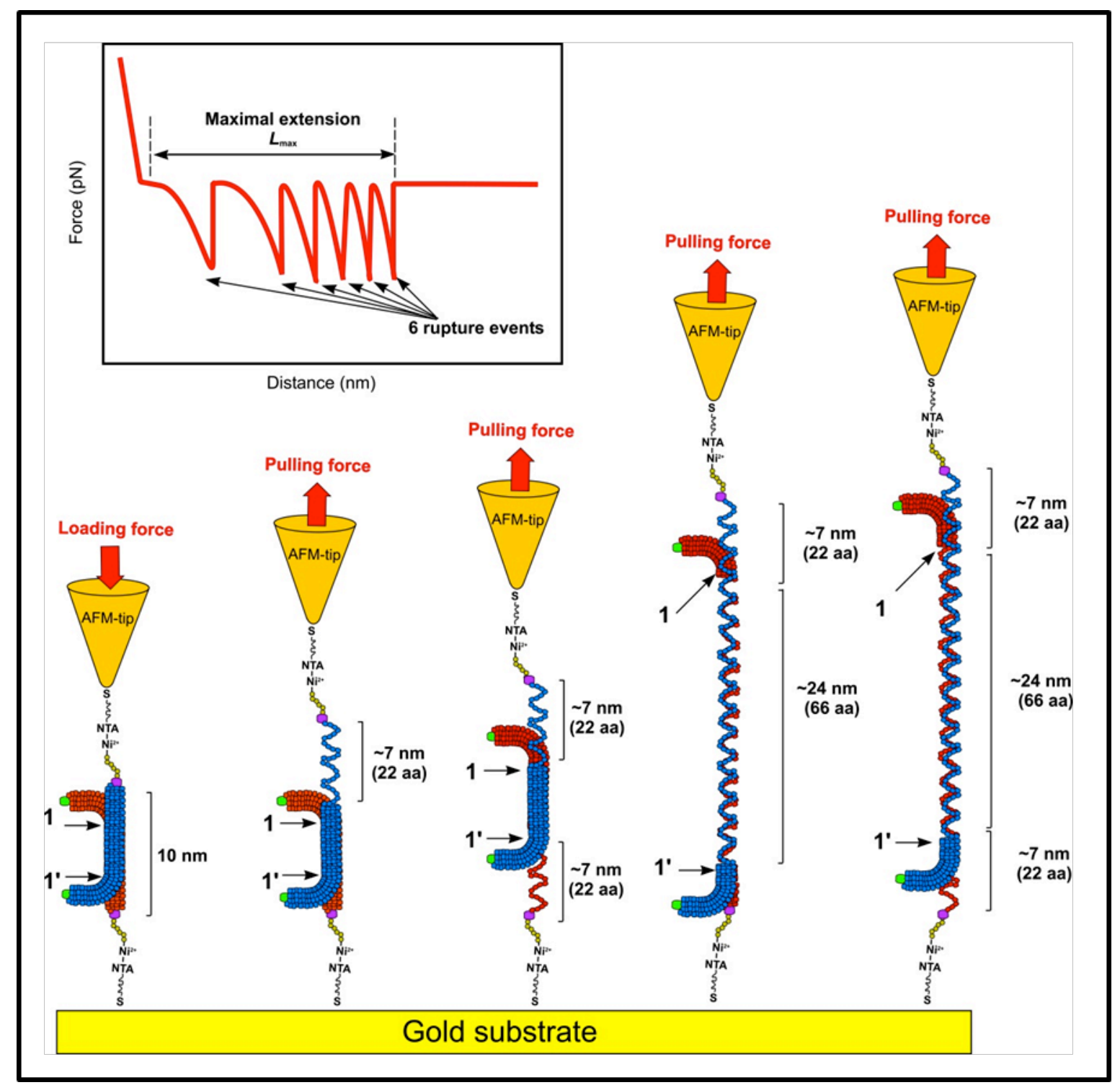

Figure 8. Schematic representation of the unfolding of trans-associated Ag43 $\alpha$ (predominant at sufficiently low values of solution pH and pulling rate). Representation of the envisaged unfolding of trans-associated $\operatorname{Ag} 43 \alpha$ dimers formed during force spectroscopy experiments. 

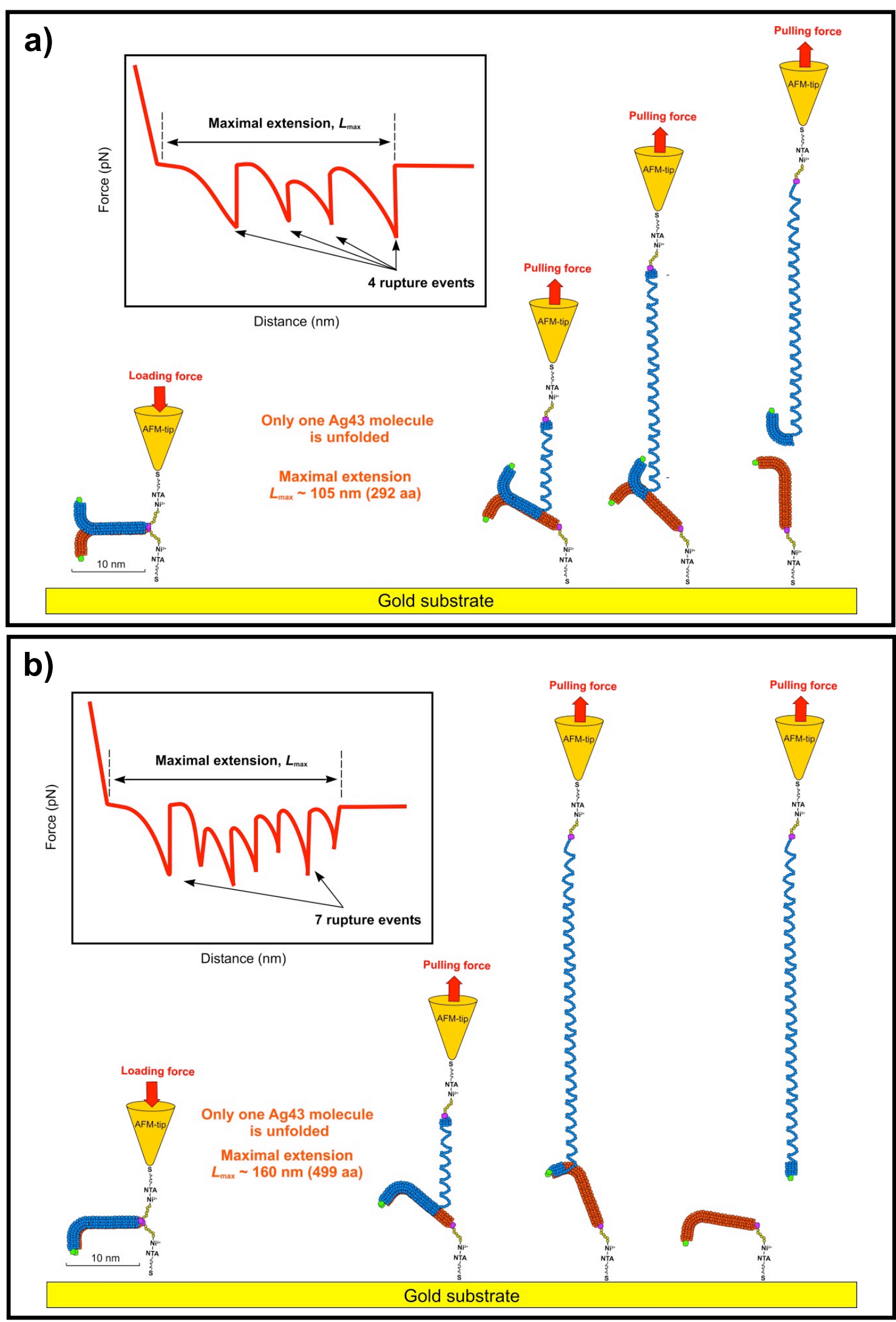

Figure 9. Schematic representation of the unfolding of cis-associated Ag43 $\alpha$ (predominant at sufficiently large values of solution $\mathrm{pH}$ and pulling rate). 
Representation of the envisaged formation and unfolding of a dimer of $\mathrm{Ag} 43 \alpha$ formed by cisinteractions. The bends of the twisted L-shaped proteins are in opposite direction a) or along the same direction $b)$.

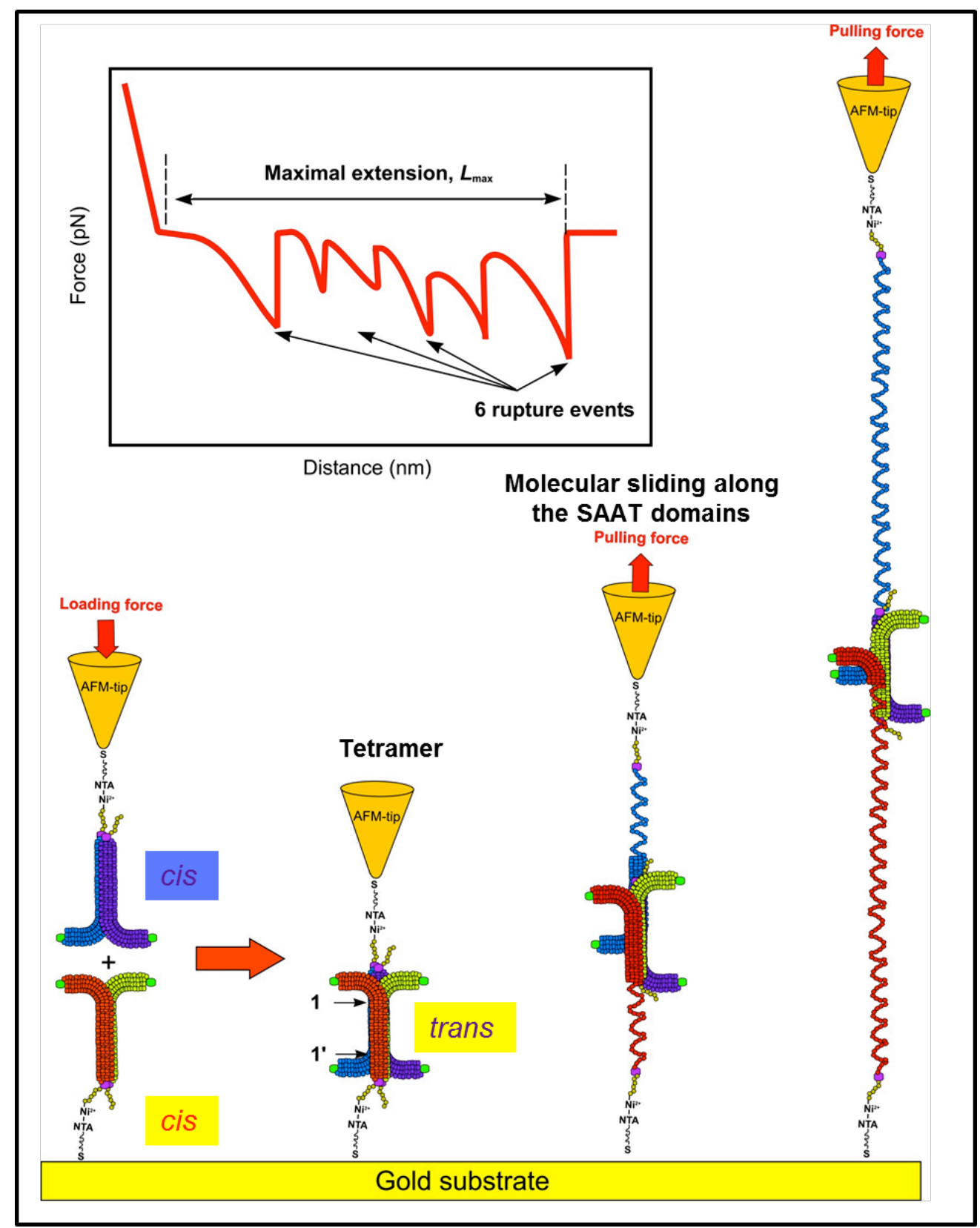

Figure 10. Schematic representation of the unfolding of Ag43 $\alpha$ tetramer.

Schematic representation of the formation and possible unfolding of a tetramer of $\mathrm{Ag} 43 \alpha$ formed by trans-interactions between two dimers in cis-configuration. 